\title{
Potential for grouper acoustic competition and partitioning at a multispecies spawning site off Little Cayman, Cayman Islands
}

\author{
Katherine C. Wilson ${ }^{1,6, *}$, Brice X. Semmens ${ }^{1}$, Christy V. Pattengill-Semmens ${ }^{2}$, \\ Croy $\mathrm{McCoy}^{3,4}$, Ana Širović, ${ }^{1,5}$
}

\author{
${ }^{1}$ Scripps Institution of Oceanography, 8622 Kennel Way, San Diego, California 92037, USA \\ ${ }^{2}$ Reef Environmental Education Foundation (REEF), PO Box 246, Key Largo, Florida 33037, USA \\ ${ }^{3}$ Cayman Islands Department of Environment, Box 10202, Grand Cayman KY1-1002, Cayman Islands \\ ${ }^{4}$ Bangor University, Bangor LL57 2DG, UK \\ ${ }^{5}$ Texas A\&M University Galveston, PO Box 1675, Galveston, Texas 77553, USA
}

${ }^{6}$ Present address: NOAA Fisheries Office of Science and Technology, 1315 East West Highway, SIlver Spring, Maryland 20910, USA

\begin{abstract}
Many fishes produce calls during spawning that aid in species and mate recognition. When multiple sound-producing species inhabit an area, the detection range may decrease and limit call function. Acoustic partitioning, the separation of calls in time, space, or spectral frequency, can minimize interference among species and provide information about fish behavior and ecology, including possible response to increasing anthropogenic noise. We investigated acoustic partitioning among 4 sound-producing epinephelids, Nassau grouper Epinephelus striatus, red hind E. guttatus, black grouper Mycteroperca bonaci, and yellowfin grouper M. venenosa, using passive acoustic data collected at Little Cayman, Cayman Islands, during the spawning season of 2015 to 2017. We measured spectral and temporal features of 9 call types known or presumed to be produced by these fishes to assess frequency partitioning and call discrimination. We assessed call temporal and spatial partitioning using recordings from 2 locations. Differences among call features enabled good discrimination of Nassau grouper and red hind but not black and yellowfin grouper. The median peak frequencies of calls differed but bandwidths shared a common $13 \mathrm{~Hz}$ range, resulting in limited partitioning of spectral space. Red hind produced calls with higher frequencies than other species. Black grouper calling peaked before sunset whereas other species' calling peaked after sunset. Yellowfin grouper calling was prevalent north of other species, suggesting spatial separation. These results indicated separation in space and time between species calls, which aids in acoustic partitioning. When this separation did not occur, unique call structures were present, which may aid in effective intraspecies communication.
\end{abstract}

KEY WORDS: Grouper - Spawning aggregation $\cdot$ Fish bioacoustics $\cdot$ Acoustic niche $\cdot$ Acoustic partitioning

\section{INTRODUCTION}

For many species of fish, sound plays a critical role in reproduction and therefore the survival and success of the species (Bass \& Mckibben 2003). Effective acoustic communication can be challenging as it requires transmission, detection, and discrimination of signals in environments that are often noisy from

\footnotetext{
${ }^{*}$ Corresponding author: katherine.c.wilson11@gmail.com
}

geophony, anthropophony, and biophony. An additional challenge for effective fish communication comes from globally increasing anthropogenic noise caused by shipping, since the frequency of many known fish sounds is in the range of boat and ship noise (Codarin et al. 2009, Slabbekoorn et al. 2010, Radford et al. 2014). A better understanding of how fish and other marine animals use the soundscape

(C) The authors 2020. Open Access under Creative Commons by Attribution Licence. Use, distribution and reproduction are unrestricted. Authors and original publication must be credited. 
and share the acoustic space (the area over which receivers can detect sound) can provide a baseline to measure effects of anthropogenic noise in these communities in addition to offering insight into the evolution and divergence of acoustic signals among species. Only a few studies have compared intra- and interspecific acoustic competition among fishes (e.g. Thorson \& Fine 2002a, Tricas \& Boyle 2014, Ruppé et al. 2015) despite there being more than 800 species from over 100 families that are known to produce sounds (Tavolga 1971, Myrberg 1981).

Effective communication for reproduction requires both species and mate recognition. Acoustic signals are used by different taxa for recognition, especially over long distances and when visual senses are limited (e.g. at night; Ryan \& Rand 1993). For example, the females of 2 African fishes Pollimyrus adspersus and $P$. isidori (Crawford et al. 1997), oyster toadfish Opsanus tau (Winn 1972, Fish 1972), and midshipman Porichthys notatus (McKibben 1999) display preferences for male conspecific calls during courtship. Furthermore, females of some species discriminate between or show preference for particular variations of acoustic features including frequency, duration, number of pulses, or level of modulation (Myrberg et al. 1986, McKibben \& Bass 2001). Stereotypical features of calls are thought to aid in species recognition, while variable features may aid in individual or mate recognition by encoding a greater level of information (Amorim et al. 2015). Since courtship sounds can play a role in sexual selection, there may be substantial pressure to ensure that these signals are distinct and easily separated from other acoustic cues in the environment. For sound, different strategies including separation of calls in time, space, or production of sound at a distinct frequency may aid in signal reception, while difference in the structure of calls may aid in the discrimination.

Acoustic partitioning in time, space, or spectral frequency may be one of the strategies that animals have adapted for effective communication. A variety of taxa including insects (Walker 1974, Sueur 2002, Henry \& Wells 2010), birds (Ficken et al. 1974, Naugler \& Ratcliffe 1994, Seddon \& Tobias 2007, Kirschel et al. 2009), frogs (Chek et al. 2003, Feng \& Schul 2007, Villanueva-Rivera 2014), bats (Chek et al. 2003, Siemens \& Schnitzler 2004, Both \& Grant 2012), and fishes (Ruppé et al. 2015) display such partitioning. These examples support the acoustic niche hypothesis (Krause 1987), which suggests that animals either produce sounds at distinct frequencies or separate sound production in time or space from other biophony to minimize interference. The known example of fish acoustic partitioning occurs between call types produced at night but not during the day, leading to the hypothesis that the availability of visual senses drives partitioning (Ruppé et al. 2015). However, the species responsible for sound production were unknown in Ruppé et al.'s (2015) study, limiting further ecological or behavioral implications to be considered. A study among species with known sound production may allow us to better understand the ecological and behavioral drivers in relation to fish acoustic partitioning.

The Epinephelidae is a family of fishes that include groupers (Ma \& Craig 2018) and many known soundproducing species (Moulton 1958, Tavolga 1968, Mann et al. 2009, 2010, Nelson et al. 2011, Schärer et al. 2012a,b, 2014, Bertucci et al. 2015) . In particular, the call types of 4 Caribbean epinephelids, the Nassau grouper Epinephelus striatus, black grouper Mycteroperca bonaci, red hind E. guttatus, and yellowfin grouper $M$. venenosa are known, including their acoustic characteristics and behavioral context (as summarized in Table 1). Recently, another likely agonistic call type produced by Nassau grouper was identified in Puerto Rico (Rowell et al. 2018). Differences in peak calling and spectral frequency of calls for each species suggest that there may be acoustic partitioning between these sympatric species. However, the recordings of the different species were not collected at the same time and were never directly compared.

The calls of these epinephelids consist of many different sounds produced in series to create a speciesspecific acoustic call structure. These different sounds (referred to as segments in this study) have been described as pulses, pulse trains, and tonal sounds. However, in most studies (e.g. Thorson \& Fine 2002b, Aalbers \& Drawbridge 2008, Mann et al. 2010, Schärer et al. 2012a,b, 2014, Tricas \& Boyle 2014, Radford et al. 2015) the peak frequency and duration of only full calls or a selected portion of the call were reported. Such measurements may not reflect the full variation of acoustic features such as frequency or bandwidth across call segments, and thus may not include valuable temporal information for call discrimination. The use of measures that capture changes in the acoustic call structure over time has increased the performance of a recently developed automated detection and classification system for epinephelids (Ibrahim et al. 2018). Additionally, many fish species discriminate temporal variability in sounds, and such variability may serve as indicators of male fitness and dominance (Amorim et al. 2015). Therefore, a more detailed analysis of the spectral and temporal features of individual call segments is of value and will help further define traits of sound 


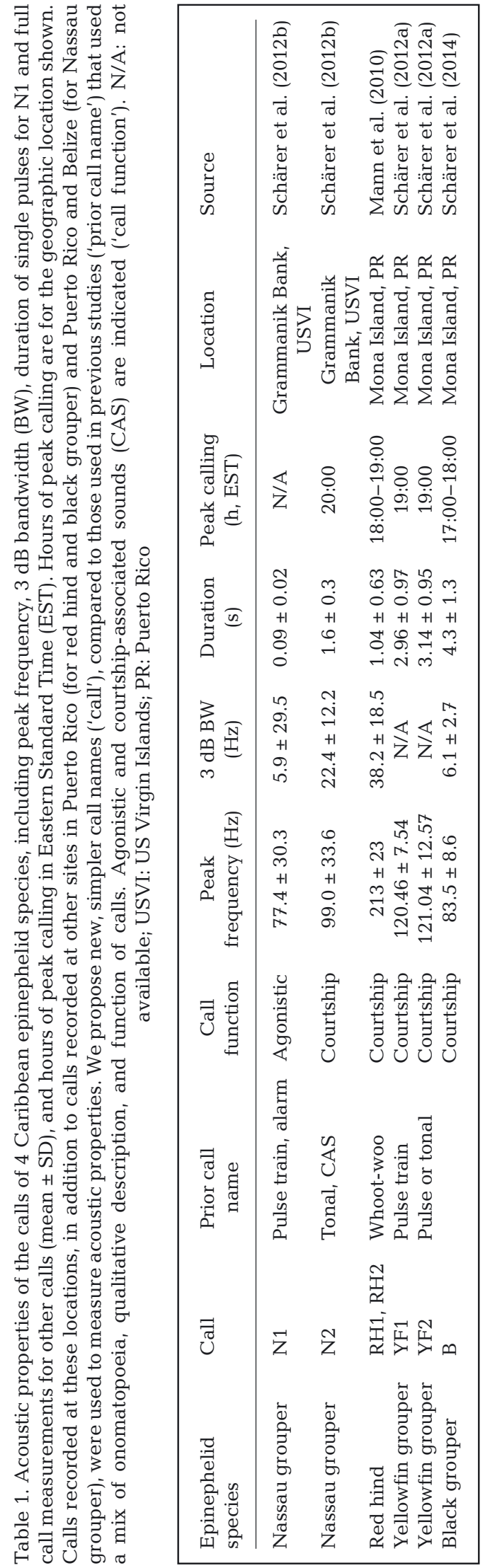

production, with implications for improved identification and detection.

To evaluate whether acoustic partitioning occurs among fishes during spawning aggregations, we investigated the details of call characteristics and call patterns in time and space amongst the 4 abovementioned epinephelid species off Little Cayman, Cayman Islands. One of the largest known remaining spawning aggregations of Nassau grouper, a Critically Endangered species (Sadovy et al. 2018), is located off the west end of Little Cayman (Whaylen et al. 2004, Heppell et al. 2012). Nassau grouper form spawning aggregations in the Cayman Islands around the full moon during the winter months, typically January and February (Sadovy \& Eklund 1999, Whaylen et al. 2004). Many other fish species spawn or display spawning-related behavior in this area during the spawning period of Nassau grouper, including red hind, black grouper, and yellowfin grouper (Whaylen et al. 2006). Since these epinephelids are known to produce courtship-associated sound (CAS), knowledge of how they share their acoustic space may lead to a better understanding of their reproductive ecology. Furthermore, it may aid in continued monitoring and management of these species as well as the discovery of other spawning aggregations (Rowell et al. 2012, 2017).

Using calls recorded during 3 consecutive winter spawning seasons of Nassau grouper off the west end of Little Cayman, we described the spectral and temporal features and the individual segments of 9 call types known or presumed to be produced by these 4 epinephelid species. We used the features and occurrences of calls at 2 sites within the fish spawning aggregation (FSA) area to evaluate whether acoustic partitioning is occurring in time, space, or frequency. Additionally, we explored the potential for discrimination of and interference between these calls based on enumerated call characteristics (i.e. the partitioning of calling based on distinct call segments), as well as the spatial and temporal trends in calling over the week of Nassau grouper spawning. This is the first study to evaluate acoustic partitioning among multiple known sound-producing fish species during the spawning season.

\section{MATERIALS AND METHODS}

\subsection{Data collection}

Passive acoustic data were collected at 2 sites located within an active FSA area off the west end of 
Little Cayman (Fig. 1) during Nassau grouper spawning in 2015, 2016, and 2017 (Table 2). Calibrated Wildlife Acoustics SM3M hydrophone recorders equipped with HTI-96 min hydrophones (-165 dB re:

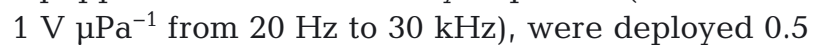
to $1 \mathrm{~m}$ above the bottom prior to spawning. Recorders were deployed in the same location at a depth of $28 \mathrm{~m}$ in 2015 and 2017 (Site B) and approximately $300 \mathrm{~m}$ north at a depth of $27 \mathrm{~m}$ in 2016 (Site A) (Fig. 1). Data were collected continuously at a minimum sample rate of $32 \mathrm{kHz}$ each year for periods of 5 to $8 \mathrm{~d}$ (Table 2). In addition to passive acoustic data, as part of the Grouper Moon Project (www.reef.org/pro grams/grouper-moon-project-protecting-caribbeanicon), divers observed and collected information about Nassau grouper spawning, the presence of other species including red hind, black grouper, and

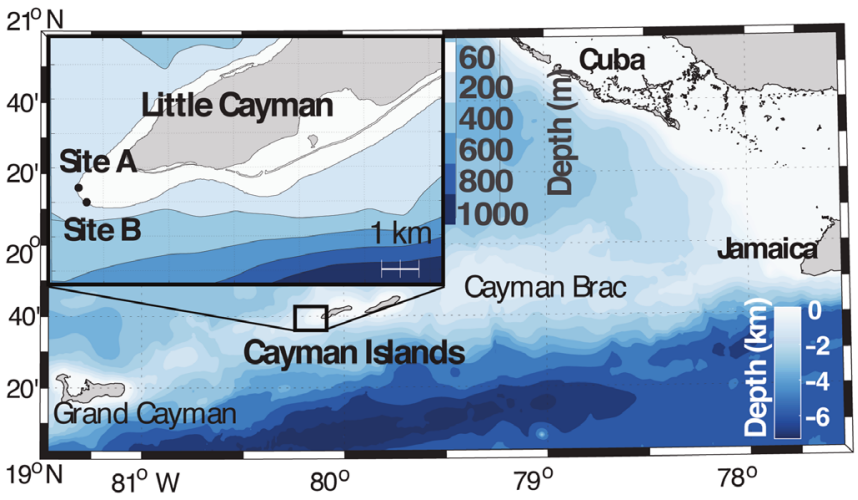

Fig. 1. Little Cayman, Cayman Islands, showing the Nassau grouper spawning sites. Inset: closer view of the west end of Little Cayman and the location of the hydrophone recorder within the fish spawning aggregation area in 2016 (Site A) and in 2015 and 2017 (Site B) yellowfin grouper, and noted any reproductive behavior of these species (Whaylen et al. 2004).

\subsection{Call description}

We analyzed the spectral and temporal features of known and presumed epinephelid calls and their individual sound segments in this study. To do so, we defined the segments more quantitatively than in previous works, based on their frequency and temporal characteristics. Pulses were short duration, narrow
Table 2. Data collection details, including the hydrophone recorder deployment year, sample rate, date interval of recordings, and dates that were manually logged for call occurrences of the 4 epinephelid species. In addition, dates of Nassau grouper spawning are marked, along with the approximate location of the spawning aggregation each year (see Fig. 1). In 2015 and 2016, Nassau grouper spawned at the location alternate to the recorder locations (e.g. in 2015 Nassau grouper spawned at Site B, while the recorder was at Site A). In 2017, Nassau grouper spawned at the same location as the array (B)

\begin{tabular}{|cccccc|}
\hline Year & $\begin{array}{c}\text { Recorder } \\
\text { location }\end{array}$ & $\begin{array}{c}\text { Sample } \\
\text { rate }(\mathrm{kHz})\end{array}$ & $\begin{array}{c}\text { Logged } \\
\text { dates }\end{array}$ & $\begin{array}{c}\text { Nassau } \\
\text { spawning }\end{array}$ & $\begin{array}{c}\text { Spawning } \\
\text { location }\end{array}$ \\
\hline 2015 & Site B & 96 & $7-12$ Feb & $7-10$ Feb & Site A \\
2016 & Site A & 32 & $21-28$ Feb & $25-28$ Feb & Site B \\
2017 & Site B & 48 & $11-19$ Feb & $13-16$ Feb & Site B \\
\hline
\end{tabular}
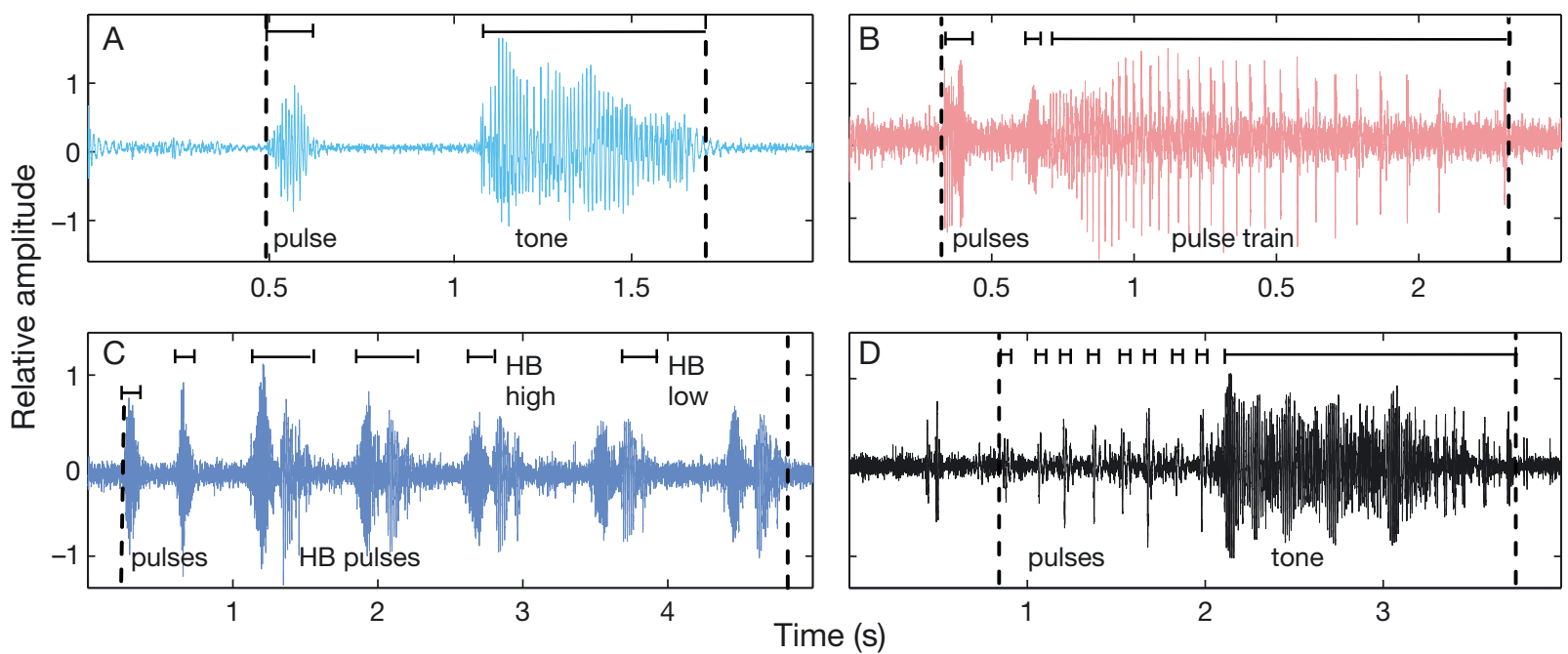

Fig. 2. Band-pass filtered (50-300 Hz) time series of 4 grouper calls with examples of the different types of call segments marked. (A) Nassau grouper courtship-associated sound (CAS) N2, consisting of a pulse and tone, (B) red hind CAS RH1, consisting of 2 pulses and a pulse train, (C) Nassau grouper agonistic sound N3, containing pulses and heartbeat (HB) pulses with the low and high HB pulse indicated, and (D) black grouper CAS constructed of pulses and a tone. Dashed lines: start and end of the full call 
bandwidth sounds that lasted on the order of $0.1 \mathrm{~s}$ (Fig. 2). Fish produced pulses in multiples or combined with other segments to form calls. Additionally, the recently confirmed Nassau grouper call type N3 (Rowell et al. 2018) can contain single pulses and dual pulse segments referred to as heartbeat pulses. The dual pulses are further described as low and high heartbeat pulses due to their different frequencies (Fig. 2B). Pulse trains consisted of multiple pulses in rapid succession that had greater bandwidth and shorter duration, approximately $0.01 \mathrm{~s}$ (Fig. 2C). The last category, tones, included tonal-like sound segments with narrow bandwidth and durations $>0.1 \mathrm{~s}$ (Fig. 2A,D). These types of sounds are not pure tones but may be complex, modulated tones or rapid pulsing that appears tonal.

To assess the possibility of acoustic partitioning of the frequency spectrum and variability between and within call types, we manually logged the occurrences of the 8 known epinephelid call types (Nassau grouper: N1, N2, N3; red hind: RH1, RH2; yellowfin grouper: YF1, YF2; black grouper: B) and an unknown call type (UNK); start and end times of calls were extracted and saved using the MATLAB software package Triton (Wiggins et al. 2010). We used logged calls from each year to create a subset of calls with relatively high signal-to-noise ratios (SNR) for each call type (Table A1 in the Appendix) that were suitable for measuring the spectral and temporal acoustic features of these calls. Call selection was constrained to a single call $\mathrm{min}^{-1}$ and 5 calls $\mathrm{h}^{-1}$ to reduce possible oversampling of persistently vocal individuals if they occurred in the monitored area. Calls from 2015 and 2017 were decimated to $32 \mathrm{kHz}$ sample frequency to be consistent with the sample frequency used in 2016, and all calls were band-pass filtered from 35 to $500 \mathrm{~Hz}$ to reduce noise from outside the call bandwidth.

We measured the following acoustic features for a subset of high SNR calls and their segments: duration, peak frequency, $3 \mathrm{~dB}$ bandwidth, received level, and (if applicable) inter-pulse period (IPP). To make these measurements, we manually selected the start and end of each call and all segments using the filtered time series of a call. Duration was defined as the time between 5 and $95 \%$ of the cumulative call energy from the selected start and end times. Peak frequency (i.e. the frequency of the maximum received level) and $3 \mathrm{~dB}$ bandwidth for full calls and each segment were measured from the power spectral density (PSD) of a call or segment after correcting for the frequency response of the recorders and hydrophones. We used a fast Fourier transform (FFT) sample size of 8192, a Hanning window, and $50 \%$ overlap to calculate the PSD. The frequencies below and above the peak frequency, where the power is reduced by half, are the upper and lower frequencies of the $3 \mathrm{~dB}$ bandwidth range, and their difference is the $3 \mathrm{~dB}$ bandwidth. Lastly, the mean time between repetitive pulse segments and pulses of pulse trains was measured to calculate IPP. When IPP was highly variable over the duration of a call, the minimum mean IPP was calculated using 3 consecutive pulses. This allowed for an easier comparison across call types.

We tested for normality of these features using Kolmogorov-Smirnov tests. Many were not normally distributed and, therefore, the median and the first and third interquartile ranges were calculated for each feature measurement for full calls and segments. Differences between the median features of call types and species were found using non-parametric Kruskal-Wallis tests and, if necessary, multiple comparisons with a Bonferroni adjustment $(\alpha<0.05)$.

\subsection{Feature variability and discrimination}

In addition to spatial and temporal partitioning of calling between species, the spectral and temporal characteristics of calls themselves may be partitioned. We investigated the use of the acoustic features of calls and segments for discriminating between species and call types using a random forest of multiple classification and regression trees (Breiman et al. 1984, Breiman 2001), which was implemented in the statistics and machine learning toolbox in MATLAB. The same number of samples was used for each call type. We combined the 2 yellowfin grouper call types into a single group for classification due to their limited occurrences and spectral similarities. The measurements for each call or segment type were randomly divided and $75 \%$ of the measurements were used for training and $25 \%$ for testing (Table A2). We used Bayesian optimization and 5-fold cross validation to find optimal settings for the random forest hyperparameters. The performance of each forest was evaluated using Fisher's exact tests $(\alpha<0.1)$ to determine if classifications were better than chance alone for calls, segments, and species classification using calls and segments. For species classification, any call or segment assigned to the right species, whether or not it was assigned to right call or segment, was considered a correct classification.

One advantage of random forests is their ability to estimate predictor variable influence on the model output, in our case call classification. When bagging is used to build a forest, each classification tree in the forest is trained from a random selection of the train- 
ing data with no replacement of these data. The outof-bag (OOB) observations (the training data not used to train a specific tree) are used to measure predictor importance by making permutations to the predictor variables (i.e. the acoustic feature measurements) and measuring the difference in the performance of the original model and the permutated models (Breiman 2001). In MATLAB, the OOB method uses the mean difference between the OOB model error of the original and each features' permutated models normalized by the standard deviation as the predictor importance estimate. If a forest trained with permutations of a single feature measurement produces higher model error than the original random forest, the feature is considered to have influence on the predictions of the original random forest. Larger differences in model error indicate stronger influence and a higher predictor importance estimate for a feature. We used this method to evaluate the importance of each feature on classification.

\subsection{Temporal calling trends}

We evaluated temporal trends in calling to assess acoustic partitioning by logging 5 to $8 \mathrm{~d}$ that spanned the nights of observed Nassau grouper spawning from each recording year. Due to the potential of certain sounds to mask calls, we logged the start and end times of anthropogenic noise (e.g. boat and diver noise) and other sources of noise (e.g. hydrophone vibrations and flow noise). These events were logged if they had relatively high received levels that occurred within the frequency range of the epinephelid calls and lasted longer than the calls. Calls and noise events were detected visually using $20 \mathrm{~s}$ spectrograms produced using a FFT length that resulted in 4 to $5 \mathrm{~Hz}$ frequency resolution and approximately $0.25 \mathrm{~s}$ time resolution. Hourly recording effort was determined by subtracting the cumulative time of all masking events from each recording hour. We normalized the total number of logged occurrences per hour for each call type by hourly recording effort to produce hourly call rates for each call type. We also calculated normalized average daily calling totals by dividing the total calls per day by daily recording effort in the same fashion as hourly totals.

\section{RESULTS}

We recorded all 8 known epinephelid call types N1, N2, N3 (Fig. 3A-C), RH1, RH2, YF1, YF2, B (Fig. 4), and UNK, which we hypothesize were produced by Nassau grouper (Fig. 3D). Recordings of all calls can be found in the Supplement at www.int-res.com/ articles/suppl/m634p127_supp/. Every year during the week of Nassau grouper spawning, occurrences of Nassau grouper and red hind were most abundant, with fewer black and yellowfin grouper calls at the FSA. Nassau grouper did not spawn at the recorder location in 2015 or 2016; spawning was at Site A and the recorder was at Site B in 2015, while spawning was at Site B and the recorder was at Site A in 2016. Nassau grouper spawned at the recording site (Site B) in 2017. Despite the difference in the location of the spawning aggregation relative to the recorder, Nassau grouper calls were recorded in all years.

A combined, normalized average of 3752, 2563, and 5816 calls d $^{-1}$ were logged for all of the known and presumed call types of the 4 grouper species in 2015, 2016, and 2017, respectively. Red hind calls were most abundant, followed by Nassau grouper, and then black grouper and yellowfin grouper. Nassau grouper call occurrences were most prevalent at Site B during 2017, when recordings were made in the immediate vicinity of the spawning aggregation, compared to the other 2 yr. Higher numbers of black grouper and red hind calls were logged at Site B in 2015 and 2017 than in 2016 at Site A. The opposite was true for yellowfin grouper calls, with a greater number of calls recorded in 2016 at Site A. The total duration of logged periods with noise was 2.73, 17.07, and $6.54 \mathrm{~h}$ for 2015, 2016, and 2017, respectively.

\subsection{Call descriptions}

The Nassau grouper alarm call, N1, was composed of a variable number of low-frequency pulses (Schärer et al. 2012b) (Fig. 3A). The CAS call, N2, consisted of a modulated tone occasionally preceded by a variable number of pulses (Fig. 3B). N3 was an agonistic call constructed of pulses and double pulse segments (Rowell et al. 2018) (Fig. 3C). Lastly, UNK included a variable number of pulses of longer duration than N1 pulses (Fig. 3D). All Nassau grouper calls, including UNK, had peak frequencies $<150 \mathrm{~Hz}$ (Fig. 5A). Calls N1 and N2 were generally lower frequency and shorter duration $(<2 s)$ than call types N3 and UNK, whose durations were approximately $3 \mathrm{~s}$ (Fig. 5A,D). The median peak frequency of UNK was significantly higher than that of the other Nassau call types (Table 3 ). However, the variability overlapped with the other Nassau grouper calls (Fig. 5A), the $3 \mathrm{~dB}$ 

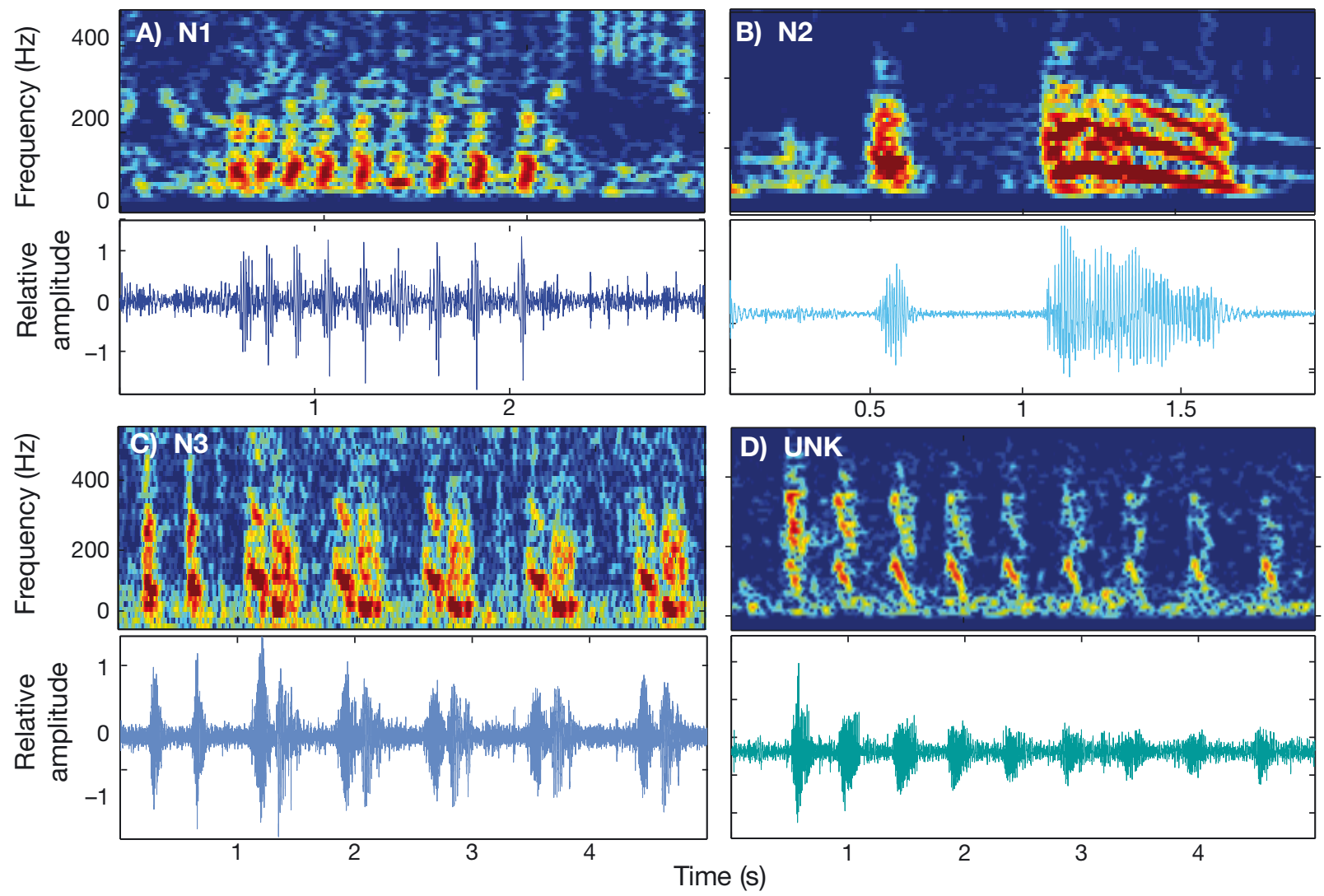

Fig. 3. Spectrograms and time series of 4 Nassau grouper call types. (A) N1: alarm call; (B) N2: courtship-associated sound call type; (C) N3: agonistic call type; (D) an unknown call (UNK) hypothesized to be a Nassau grouper call. All spectrograms were produced using a fast Fourier transform sample size of 8192, a Hanning window, and $50 \%$ overlap. Time series were bandpass filtered from $20-500 \mathrm{~Hz}$ using an elliptical filter. See Supplement for recordings

bandwidth was similar to other Nassau grouper calls (Fig. 5C), while the bandwidth was similar to the high frequency heartbeat pulse of N3 (Fig. 5D).

Red hind call RH1 had a more stereotypical call structure than RH2, consisting of 2 pulses followed by a pulse train with increasing IPP (Fig. 4A). The common structure of $\mathrm{RH} 2$, albeit variable, was a pulse, pulse train, and a tone (Fig. 4B). The median peak frequency of the full RH1 call was slightly higher than that of RH2, but the frequencies of individual segments varied (Fig. 5A). The RH1 call was substantially shorter than RH2 (Fig. 5E). Yellowfin grouper calls included YF1, composed of pulse trains, and YF2, composed of at least one tonal segment that was variably combined with other tones, pulses, or pulse trains (Fig. 4C,D). Black grouper call B was formed by at least one modulated tone preceded or followed by a variable number of pulses (Fig. 4E). Black grouper calls had the lowest median peak frequency and $3 \mathrm{~dB}$ bandwidth of all calls (Fig. 5A,B).

Even though the bandwidth range of all calls covered the 112 to $125 \mathrm{~Hz}$ frequency band (Fig. 5C), there were significant differences between the median peak frequency $\left(\chi^{2}=279.3, \mathrm{df}=8, \mathrm{p}<0.001\right), 3 \mathrm{~dB}$ bandwidth $\left(\chi^{2}=222.1, \mathrm{df}=8, \mathrm{p}<0.001\right)$, duration $\left(\chi^{2}=429.8, \mathrm{df}=8, \mathrm{p}<0.001\right)$, and IPP $\left(\chi^{2}=708.7, \mathrm{df}=\right.$ $10, \mathrm{p}<0.001$ ) of the 8 call groups (Table 3 ). Black grouper calls had the lowest median peak frequency (86 Hz), while RH1 calls had the highest $(154 \mathrm{~Hz})$, and both had peak frequencies that differed significantly from 6 of the 7 other call types (Fig. 5A, Table 3). Full call bandwidth was again lowest, i.e. most narrow, for black grouper calls and widest for RH1 calls (Fig. 5B). The greatest variability in peak frequency was observed in red hind call RH2 (quartile range 86 to $211 \mathrm{~Hz}$ ). RH2 peak frequency overlapped with the median peak frequency of RH1, yellowfin grouper calls (129 Hz), Nassau grouper call N3 $(119 \mathrm{~Hz})$ and UNK $(133 \mathrm{~Hz})$, and there were no significant differences between the median peak frequencies of RH2 and the latter 3. Interestingly, the one segment with a substantially different frequency range (both in peak frequency and $3 \mathrm{~dB}$ bandwidth) was the pulses of the red hind calls (Fig. 5D). 

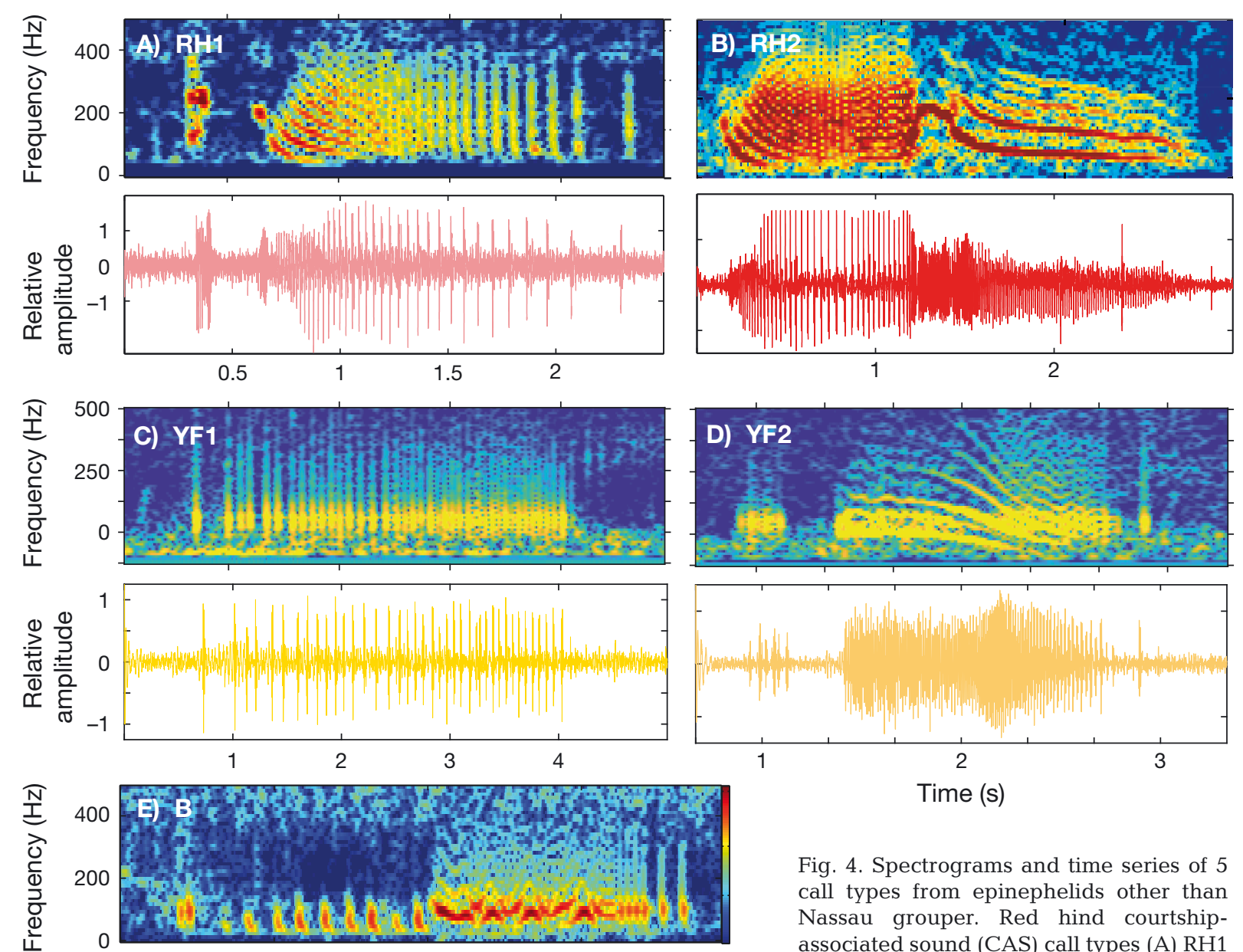

Fig. 4. Spectrograms and time series of 5 call types from epinephelids other than Nassau grouper. Red hind courtshipassociated sound (CAS) call types (A) RH1 and (B) RH2; yellowfin grouper CAS call types (C) YF1 and (D) YF2; (E) black grouper CAS call type B. All spectrograms were produced using a fast Fourier transform sample size of 8192, a Hanning window, and $50 \%$ overlap. Time series were bandpass filtered from $20-500 \mathrm{~Hz}$ using an elliptical filter. See Supplement for

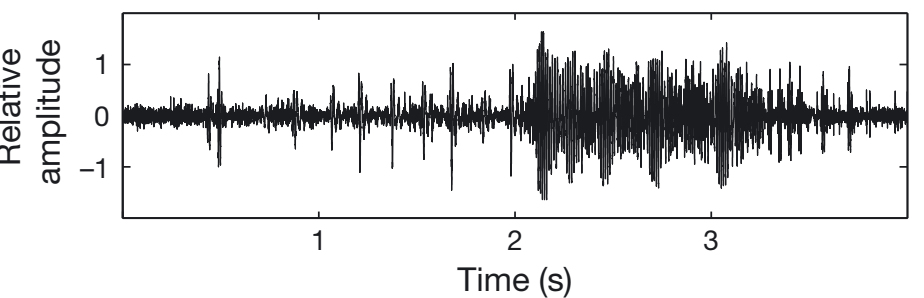
recordings

The duration of Nassau grouper calls N1 and N2 and the red hind call RH1 was significantly shorter than the other call types, with the exception of YF2 for N1 (Fig. 5E, Table 3). The median IPP was smallest for pulse trains of RH1 (0.015 s) and largest for heartbeat pulses of N3 (0.8 s) (Fig. 5F), but both red hind calls RH1 and RH2 had median IPPs significantly lower than all other call types except the yellowfin grouper calls (Table 3). All Nassau grouper pulses, with the exception of heartbeat pulses, had similar IPP measurements, and they were significantly higher than the median IPP of other calls (Table 3). The median IPPs of black grouper pulses and yellowfin grouper pulses and pulse trains were similar to each other, yet only black grouper IPP were significantly higher than the IPP of red hind calls (Table 3).

\subsection{Feature variability and call discrimination}

IPP and duration were the most important predictors for random forests, influencing both call and segment classification more strongly than spectral features. For call classification, the normalized average increase in model error for random forests trained with permutated feature measurements compared to the random forest trained with true feature measurements was 3.78 for IPP and 3.74 for duration compared to $<1$ for spectral features. Similarly, for seg- 

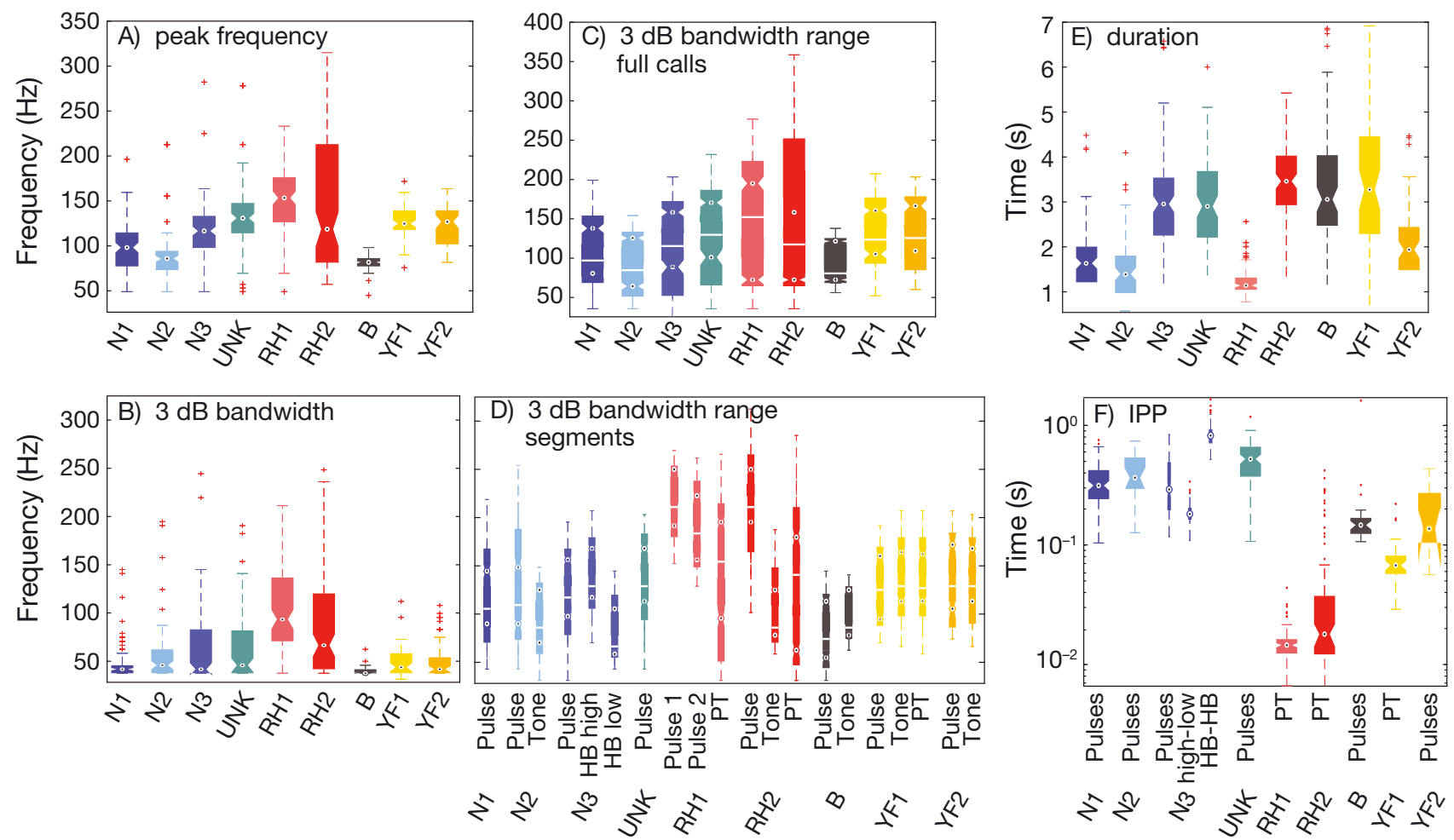

Fig. 5. Median (black dots) and quartile ranges (boxes) for (A) peak frequency, (B) $3 \mathrm{~dB}$ bandwidth, (C,D) the lower and upper frequencies of the $3 \mathrm{~dB}$ bandwidth range with peak frequency shown by the white bar for (C) full calls and (D) call segments, and (E) full call duration and (F) inter-pulse period (IPP) feature measurements. Segment types including heartbeat (HB) pulses and pulse trains (PT) are shown along the $x$-axis for measurements that are not for full calls. Dashed lines extend to $\pm 2.7 \sigma$; red crosses: outliers; notches around the median: $95 \%$ CI based on sample size

Table 3. Statistically significant differences between the median features of epinephelid call types. Significant differences $(p>0.05)$ in peak frequency (f), $3 \mathrm{~dB}$ bandwidth (b), duration (d), and inter-pulse period (i) are shown between call types. (-) No difference

\begin{tabular}{|lllllllll|}
\hline Call & N1 & N2 & N3 & UNK & RH1 & RH2 & B & YF1 \\
\hline N2 & - & & & & & & & \\
N3 & d, i & f, d, i & & & & & & \\
UNK & f,d & f, d & i & & & & & \\
RH1 & f, b, d, i & f, b, i & f, b, d, i & b, d, i & & & & \\
RH2 & f, b, d, i & f, b, d, i & b, i & i & f, b, d & & & \\
B & f, d, i & b, d, i & f, b, i & f, b, i & f, b, d, i & f, b, i & & \\
YF1 & f, d, i & f, d, i & i & i & f, b, d & b & f & \\
YF2 & f & f, d & d, i & d, i & b, d, i & b, d & f, b, d & d \\
\hline
\end{tabular}

ment classification the normalized average increase in mean model error was 4.64 for IPP, 1.85 for duration, and $<1.16$ for spectral features.

On average, the random forest for call classification performed slightly better than the forest for segment classification. Each classified over half of all calls or segments correctly (64 and $60 \%$, respectively). Species classification performance was greater than call or segment classification with over three-quarters of the calls and segments assigned correctly ( $78 \%$ of calls and $76 \%$ of segments). Call and segment classification was greater than chance for all calls and segments with the exception of $\mathrm{N} 2$ pulses $(\mathrm{df}=16, \mathrm{p}=$ 0.3 ) and both performed better than chance for all species (Table 4). Nassau grouper and red hind calls and segments were assigned correctly more often than black and yellowfin grouper calls and segments. Additionally, species identification of Nassau grouper and red hind was slightly greater when using segments (94 and 92\%, respectively), compared to 91 and $84 \%$ for calls. The opposite was true for identification of black and yellowfin grouper, which was slightly greater when using calls (76 and $61 \%$, respectively) compared to segments (61 and 58\%) (Table 4).

Red hind calls had the highest average classification accuracy for call types, with $93 \%$ of RH1 and 
Table 4. Classification performance for epinephelid calls and segments. Percentage of correct classifications are shown for calls, segments, and species classification using both calls and segments. The chance of predicting calls was $12.5 \%$, segments $6 \%$, and species $25 \%$. Yellowfin grouper pulses were excluded from this analysis due to low sample size

\begin{tabular}{|c|c|c|c|c|c|c|c|c|c|c|c|c|c|}
\hline Call & $\begin{array}{c}\% \\
\text { Correct }\end{array}$ & $\mathrm{p}$ & $\chi^{2}$ & $\begin{array}{c}\% \text { Species } \\
\text { correct }\end{array}$ & $\mathrm{p}$ & $\chi^{2}$ & Segment & $\begin{array}{c}\% \\
\text { Correc }\end{array}$ & $\mathrm{p}$ & $\chi^{2}$ & $\begin{array}{c}\% \text { Species } \\
\text { correct }\end{array}$ & $\mathrm{p}$ & $\chi^{2}$ \\
\hline N1 & 77 & $<0.001$ & 98.7 & & & & Pulses & 54 & $<0.001$ & 108.0 & & & \\
\hline N2 & 32 & $<0.001$ & 7.51 & & & & $\begin{array}{l}\text { Pulses } \\
\text { Tones }\end{array}$ & $\begin{array}{c}0 \\
77\end{array}$ & $\begin{aligned} & 0.3 \\
< & 0.001\end{aligned}$ & $\begin{array}{c}1 \\
202.5\end{array}$ & & & \\
\hline N3 & 53 & $<0.001$ & 45.73 & 91 & $<0.001$ & 238.2 & $\begin{array}{l}\text { Pulses } \\
\text { HB high } \\
\text { HB low }\end{array}$ & $\begin{array}{l}27 \\
83 \\
83\end{array}$ & $\begin{array}{l}<0.001 \\
<0.001 \\
<0.001\end{array}$ & $\begin{array}{c}20.8 \\
325.1 \\
325.1\end{array}$ & 94 & $<0.001$ & 26.8 \\
\hline UNK & 54 & $<0.001$ & 38.1 & & & & Pulses & 71 & $<0.001$ & 182.9 & & & \\
\hline RH1 & 93 & $<0.001$ & 158.4 & 84 & $<0.001$ & 103.7 & $\begin{array}{c}\text { Pulse } 1 \\
\text { Pulse } 2 \\
\text { Pulse train }\end{array}$ & $\begin{array}{l}48 \\
85 \\
70\end{array}$ & $\begin{array}{l}<0.001 \\
<0.001 \\
<0.001\end{array}$ & $\begin{array}{c}87.1 \\
306.7 \\
202.8\end{array}$ & 92 & $<0.001$ & 12.1 \\
\hline RH2 & 69 & 0.01 & 85.54 & & & & $\begin{array}{c}\text { Pulses } \\
\text { Tones } \\
\text { Pulse trains }\end{array}$ & $\begin{array}{l}59 \\
59 \\
79\end{array}$ & $\begin{array}{l}<0.001 \\
<0.001 \\
<0.001\end{array}$ & $\begin{array}{l}145.7 \\
145.7 \\
282.4\end{array}$ & & & \\
\hline B & 76 & 0.5 & 78.88 & 76 & $<0.001$ & 29.5 & $\begin{array}{l}\text { Pulses } \\
\text { Tones }\end{array}$ & $\begin{array}{l}50 \\
67\end{array}$ & $\begin{array}{l}<0.001 \\
<0.001\end{array}$ & $\begin{array}{c}35.1 \\
140.2\end{array}$ & 61 & 0.1 & 2.77 \\
\hline YF & 61 & $<0.001$ & 67.47 & 61 & $<0.001$ & 21.8 & $\begin{array}{c}\text { Tones } \\
\text { Pulse trains }\end{array}$ & $\begin{array}{l}57 \\
53\end{array}$ & $\begin{array}{l}<0.001 \\
<0.001\end{array}$ & $\begin{array}{c}132.9 \\
61\end{array}$ & 58 & $<0.001$ & 25.2 \\
\hline
\end{tabular}

$69 \%$ of RH2 calls correctly predicted. On the other hand, Nassau grouper calls N2 and N3 and UNK had the lowest performance with 32,53 , and $54 \%$ of calls correctly assigned, respectively (Table 4 ). The majority of incorrect classifications for these calls types were incorrectly assigned to each other or the other Nassau grouper call type: 41 and $15 \%$ of $\mathrm{N} 2$ calls and 21 and $17 \%$ of UNK calls were classified as N1 and $\mathrm{N} 3$, respectively, and $33 \%$ of N3 calls were assigned to
UNK (Fig. 6A). Similarly, for other species' calls, the incorrect classifications were most often assigned to Nassau grouper calls as well, with the exception of yellowfin grouper. Red hind call RH2 was classified as N3 call type $21 \%$ of the time and $14 \%$ of black grouper calls were classified as N1 call types. In contrast, yellowfin grouper calls were equally misclassified as red hind call RH1 and N1 calls $13 \%$ of the time (Fig. 6A).
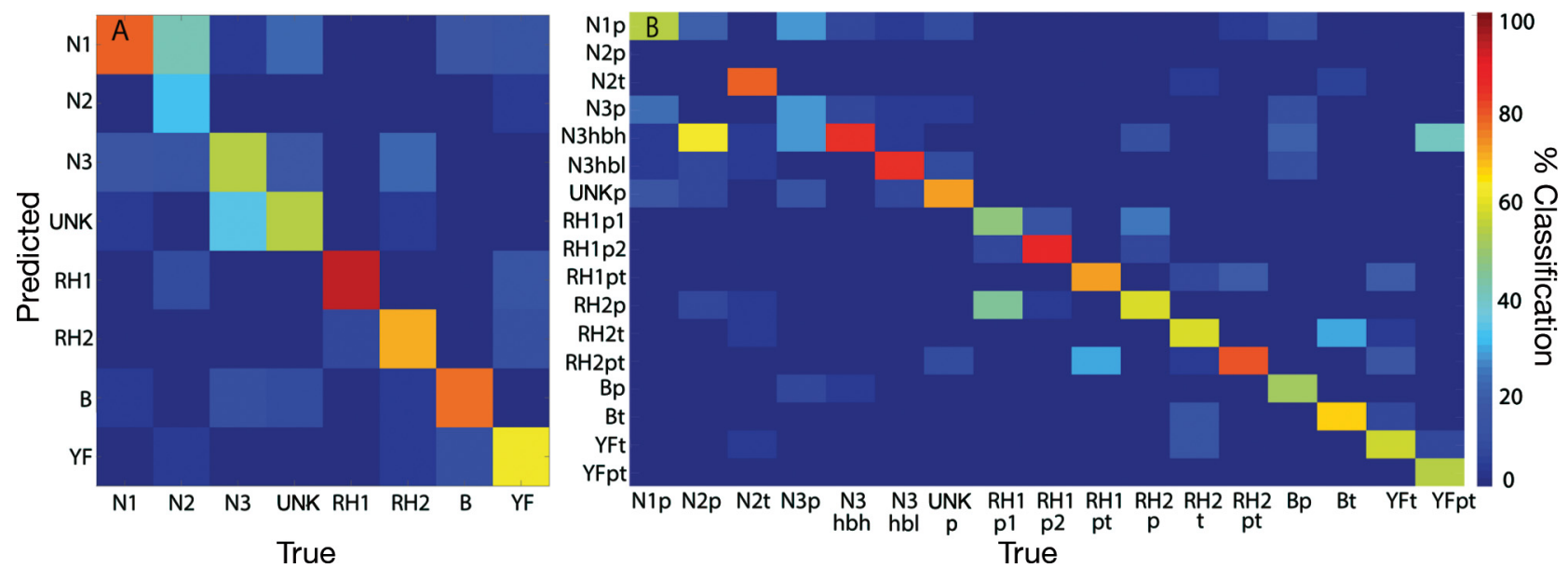

Fig. 6. Confusion matrices showing the random forest classification results for epinephelid (A) call and (B) segment classification (see Table 1 for call definitions). Predictions for each call or segment type are shown across the column with correct predictions along the diagonal. Type of segment is indicated by the letter following the name: p: pulses; t: tones; hbh: heartbeat high pulse; hbl: heartbeat low pulse; pt: pulse trains 
Segment classification indicated which segments were similar or distinct according to these acoustic features. The heartbeat pulses of Nassau grouper call $\mathrm{N} 3$ and the second pulse of red hind call RH1 had the highest classification accuracy with 83 and $85 \%$ correctly assigned, respectively. The lowest performance was observed for N2 and N3 pulses, 0 and $27 \%$ correct assignments, respectively. Similar to calls, the majority of these segments were assigned to other Nassau grouper call segments: $62 \%$ of N2 pulses and $27 \%$ of N3 pulses were assigned as N3 heartbeat high pulses and another $19 \%$ of N2 pulses and $27 \%$ of N3 pulses were assigned as N1 pulses. For all other call segments, 48 to $79 \%$ of their segments were correctly classified (Fig. 6B). However, red hind segments also had many incorrect classifications within species: the first pulse and pulse train of RH1 was classified as RH2 pulses and pulse trains, respectively, 44 and $30 \%$ of the time. Black and yellowfin grouper had segments that were often assigned to other species: $29 \%$ of black grouper tones were classified as RH2 tones and $40 \%$ of yellowfin grouper pulse trains were classified as N3 pulses.

\subsection{Temporal calling trends}

The trends in daily call occurrences varied between the years and sites for these species. Red hind calling increased over the deployment duration, peaking after Nassau grouper spawning in 2015 and 2017 at Site B. This was not observed at Site A in 2016. Nassau grouper calling (mostly consisting of N2 calls) was an order of magnitude higher in 2017 $\left(2072\right.$ calls d $\left.^{-1}\right)$, when recordings were made in the immediate vicinity of the spawning aggregation compared to the other 2 yr (77 and 239 calls d $^{-1}$ in 2015 and 2016, respectively; Fig. 7). Despite the increase in N2 calls in 2017, red hind calls were still

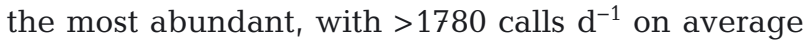
each year. Yellowfin and black grouper calls were less abundant than red hind and Nassau grouper calls. Overall, higher numbers of red hind calls were logged at Site B in 2015 and 2017 than in 2016 at Site A. The highest numbers of yellowfin grouper calls, 69 calls $\mathrm{d}^{-1}$, were recorded at Site A in 2016, versus 23 calls d $^{-1}$ in 2015, and 61 calls d $^{-1}$ in 2017 at Site B. In contrast, black grouper call totals were high at Site B
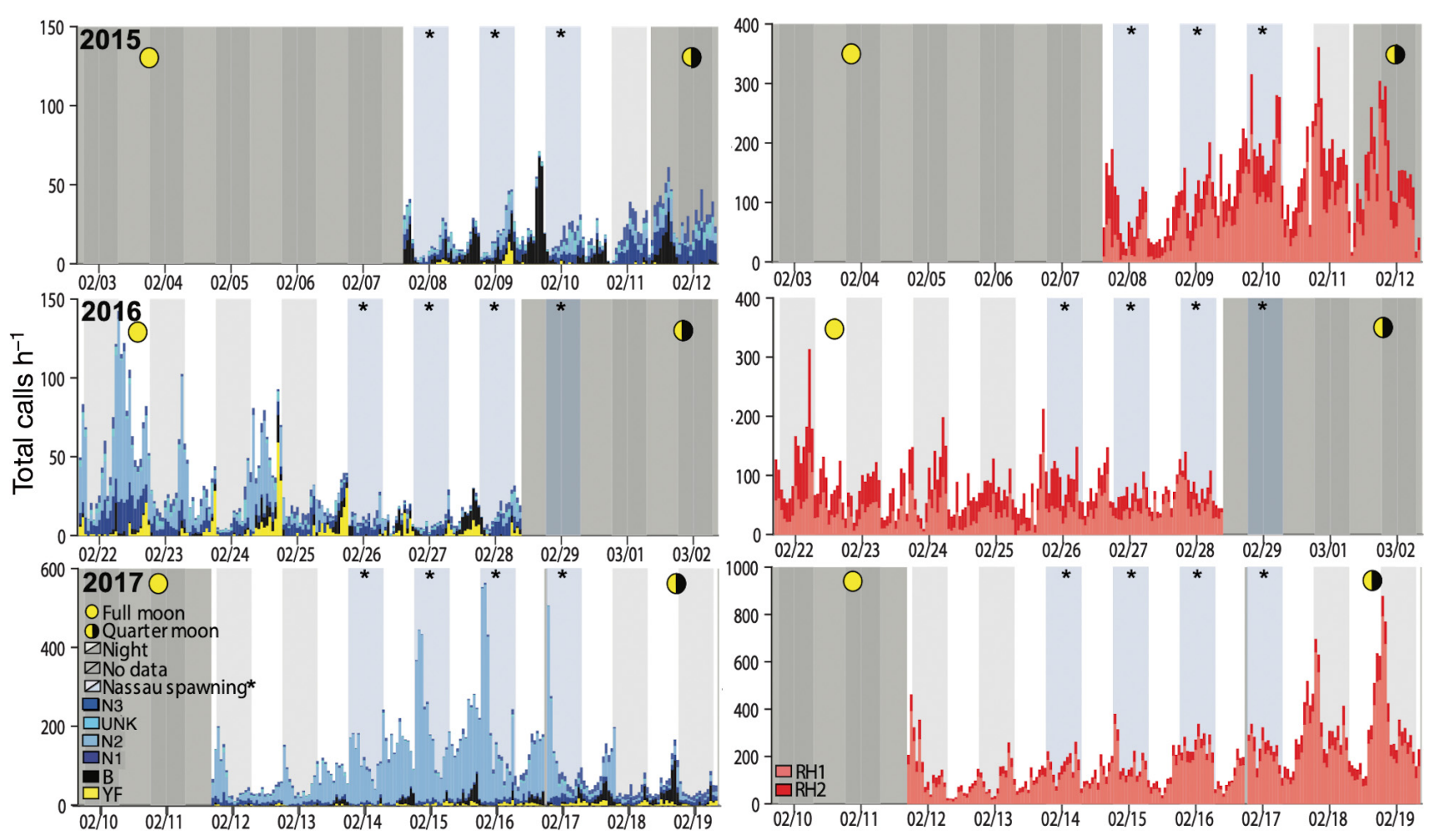

Fig. 7. Hourly occurrences (normalized by effort) of 9 epinephelid call types during the period of Nassau grouper spawning in 2015, 2016, and 2017. Nassau grouper calls (N1, N2, N3), the unknown call (UNK), black grouper call (B), and a combined total for yellowfin grouper calls YF1 and YF2 (YF) are shown on the left. Red hind calls RH1 and RH2 are shown on the right. The length of each colored bar indicates the effort-normalized number of calls occurring each hour for an individual call type; combined, they show the sum of the call types plotted. The time between sunset and sunrise is marked either by blue or grey columns, with blue indicating nights of observed Nassau grouper spawning. Dark grey indicates where data was not collected 
in 2015 and 2017 (148 and 130 calls d $^{-1}$, respectively) and lower at Site A in 2016 (57 calls d ${ }^{-1}$ ).

There were diel patterns in the call production of all red hind, yellowfin, and black grouper calls, as well as Nassau grouper N2 calls (Fig. 8). The patterns for N2 and YF varied from year to year, likely due to the change in proximity of spawning aggregations to the recorder location. During 2017, N2 calling peaked $2 \mathrm{~h}$ after sunset and remained elevated $4 \mathrm{~h}$ after sunset. In 2015 and 2016 (when the hydrophone recorder was relatively distant from the location of evening Nassau grouper spawning), N2 calling was
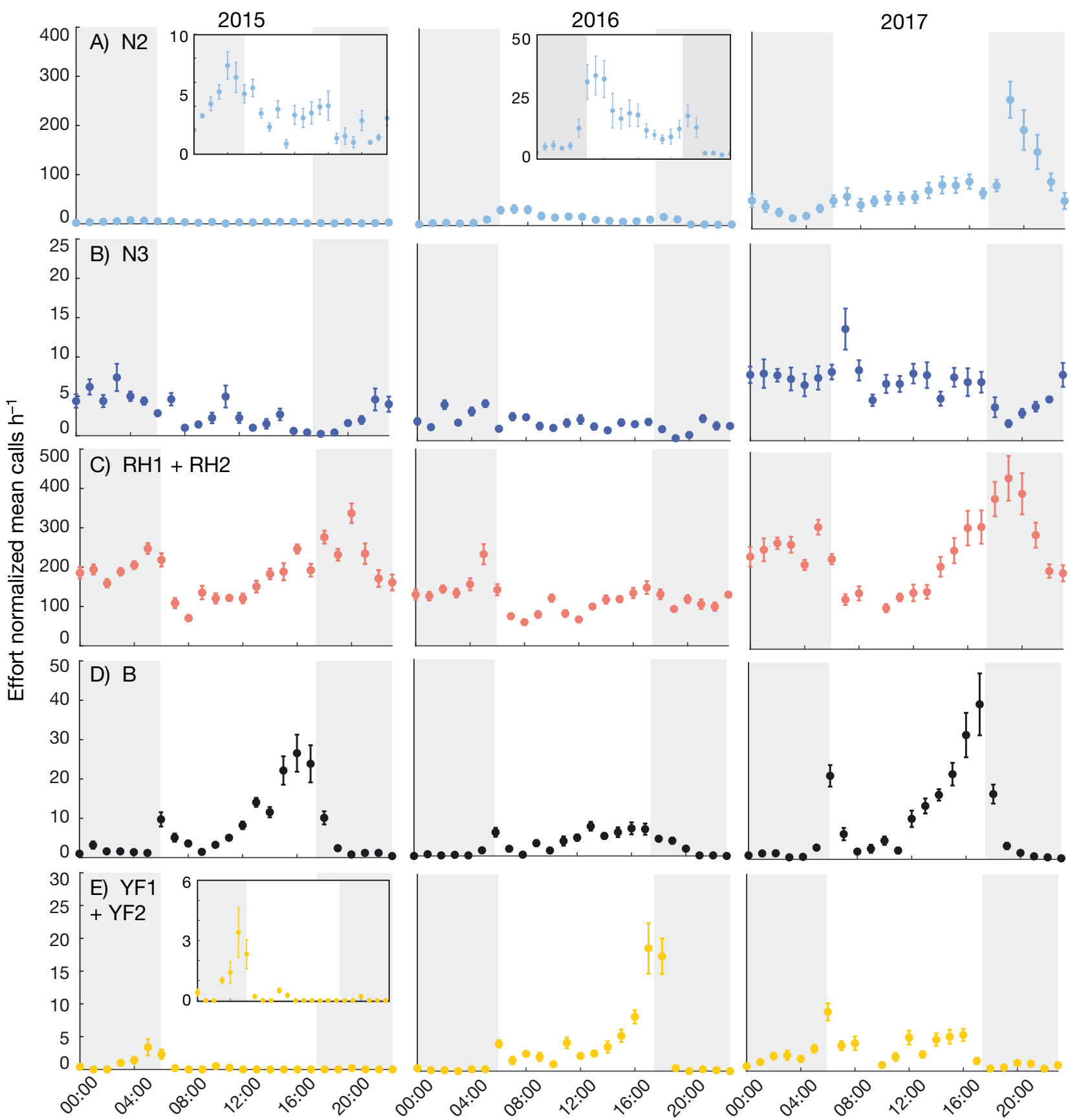

Time (EST)

Fig. 8. Mean $\pm 95 \%$ confidence interval hourly calling rates for 5 call types of 4 epinephelid species during the period of Nassau grouper spawning in 2015, 2016, and 2017. (A) Nassau grouper courtship-associated sound (CAS) call type N2, (B) Nassau grouper agonistic call type N3, (C) combined red hind calls RH1 and RH2, (D) black grouper call B, and (E) combined yellowfin grouper calls YF1 and YF2. Grey background: nighttime, the time between sunset and sunrise; white background: daytime 
highest around sunrise and decreased over the day with the lowest number of calls near sunset (Fig. 8B). Occurrences of the remaining Nassau grouper calls (N1 and N3) and UNK decreased after sunset on the days Nassau grouper were known to spawn. There was a change in the diel patterns of yellowfin grouper calling between the 2 locations. Peak calling occurred around sunset at Site A in 2016 and at sunrise at Site B in 2015 and 2017 (Fig. 8E). The other 3 call types, RH1, RH2, and B, had relatively consistent patterns across years. The diel pattern of red hind calls RH1 and RH2 were comparable and therefore combined. Red hind calling was most abundant $1 \mathrm{~h}$ before sunrise and 2 to $3 \mathrm{~h}$ after sunset each year (Fig. 8C). In 2016, the peak at sunrise was more pronounced than the peak at sunset, but the opposite was true for 2015 and 2017. The number of black grouper calls were higher at Site B than Site A. There was a small increase in calling at sunrise but the greatest peak in calling occurred 1 to $2 \mathrm{~h}$ before sunset and decreased after sunset each year (Fig. 8D).

\section{DISCUSSION}

We recorded an abundance of epinephelid calls during the winter spawning of Nassau grouper off Little Cayman. There was indication that the calls of 4 species of groupers were separated in time, space, or frequency. Differences in the acoustic features frequency, bandwidth, IPP, and duration allowed calls of Nassau grouper and red hind to be discriminated relatively well, but black and yellowfin grouper calls were more difficult to distinguish. Other call features not considered here (such as modulation) may aid in discriminating the calls of these 2 species, and in practical applications their spatial partitioning, which is likely driven by FSA dynamics, can aid in separating the calls. Partitioning of acoustic space among these grouper species likely occurs through a combination of ways: red hind calls were distinguishable in spectral frequency, black grouper calls were separated by time of occurrence during the day, and more yellowfin grouper calls were recorded at Site A than Site B (where Nassau grouper have been observed spawning since 2001, with the exception of 2016).

\subsection{Call description}

Overall, 8 of the 9 call types detailed here (N1, N2, N3, RH1, RH2, B, YF1, and YF2) were previously identified in the Caribbean as being produced by grouper species (Mann et al. 2010, Schärer et al. 2012a,b, 2014, Rowell et al. 2018). We hypothesized that one other call type, UNK, was produced by Nassau grouper due to its spectral and temporal similarity with known Nassau grouper calls. However, without tight coupling of location of calling animals and visual confirmation of species at that location, this theory remains untested. Also, it is unknown whether these species produce other sounds or if other fish species present in the area, such as tiger grouper Mycteroperca tigris, produce any sounds. Incorrect classifications or inclusion of sounds produced by another species could create higher variability in our measurements. Further work, for example using paired visual and audio identification, are needed to confirm our hypothesis for the UNK call, determine if these grouper or other grouper produce other sounds and call types, and identify all behaviors associated with each call type.

For many sympatric species including fish (Crawford et al. 1997), variation between calls may aid in identification of conspecifics and heterospecifics (Ryan \& Rand 1993). While it is not known which acoustic features these species are most perceptive or sensitive to, some fishes can discriminate between varying IPP (Fay \& Popper 2000). Our results suggest that IPP could be useful to discriminate Nassau grouper and red hind calls from other species if these grouper can perceive this feature. In addition to IPP, duration and spectral features also proved to be promising for differentiating among some call types and species. For example, black grouper and red hind call RH1 have one or more spectral features that differ significantly from all other calls types, yellowfin grouper calls have at least one feature that differs from the calls of other species, and duration differs among call types of the same species. Most likely the fish use a combination of these spectral and temporal features, as well as patterning of different segments for such discrimination. However, to test which features aid in discrimination, further work on hearing sensitivity and sound perception is necessary.

Additionally, the function of these sounds is not fully understood and is difficult to study. During spawning aggregations when fish are in close proximity to each other, other cues (visual or chemical) are likely sensed as well, and this type of multisignaling may make it challenging to determine the true function of the sound. The production of these calls outside aggregations raises questions about their function and points to the possibility of multiple functions for a sound. While associating function with 
these signals was beyond the scope of this study, the structure of call segments may offer further insight to their possible function. Since many calls overlap in frequency, the patterns of segments including the timing and frequency variations allow each call to be unique and may aid in species identification. Furthermore, similar segments within species may also aid in species identification, and the distinct segments within species may be more representative of a specific behavioral context.

Red hind calls had segments that were spectrally separated from the call segments of other species. This separation may be driven by frequency partitioning or it may be a result of factors related to function or physiology. However, this separation likely helps facilitate intraspecies communication given the spatial overlap of red hind with all other species. Red hind form diffuse spawning aggregations over larger areas than the other 3 species (Shapiro et al. 1993), making them more likely to overlap in space with the spawning aggregations of the other species. The call trends indicated they are not spatially segregated from Nassau grouper off Little Cayman, nor are they separated from the other 3 species elsewhere in the Caribbean (Beets \& Friedlander 1999, Luckhurst 2010, Schärer et al. 2012a). Furthermore, physiological and ecological constraints likely affect the variation observed among features (Bradbury \& Vehrencamp 2011). The low bandwidth may be a physiological restraint, whereas the high variance among durations, with the exception of RH1, may convey information about the individual fitness and motivation of callers (Bass \& Ladich 2008).

Though the spectral features of these calls aid in automated species identification by a machine in some cases, they do not provide much evidence for frequency partitioning among all species. Unlike previous studies that assessed frequency partitioning using only peak frequency, we investigated both the peak frequency and the $3 \mathrm{~dB}$ bandwidth of calls, because the majority of energy within a call is contained within this bandwidth. There are significant differences among the peak frequencies of some call types, but most calls share the part of the spectrum between 112 and $125 \mathrm{~Hz}$, except some red hind call segments. This is similar to what was previously observed in fish calls produced during the day as opposed to night in a submarine cave in South Africa (Ruppé et al. 2015). In that case, competition for acoustic space could be mitigated by the ability to visually identify callers during the daytime. Since these epinephelids spawn around sunset and produce the highest number of calls at night, visual cues by themselves may not allow for identification of callers during this time. It has been proposed that spawning may occur at this time to take advantage of the lower visibility, possibly as a predator avoidance adaptation. Furthermore, the range of peak frequencies and bandwidth observed for these calls suggest that these species will be limited in their ability to compete with anthropogenic noise from shipping and boating, which occurs in the same frequency band as these calls. However, the hearing sensitivities of these grouper and the sound levels and range of the noise source and the grouper calls will all determine whether there is competition.

\subsection{Feature variability and call discrimination}

Similar to the results of the call measurements, classification using random forests indicated that IPP and duration had the strongest influence on call discrimination predictions. Examination of a number of the trees used to build the random forests showed that these 2 features were used at the highest branches of the trees, whereas spectral features were used at the lower branches. This suggests that temporal features of calls could aid in species recognition more than frequency or bandwidth. However, both temporal and spectral features were needed to distinguish the call types and segments, indicating that those parameters may also be used by these species to further interpret the signals if the fish can perceive those features.

The acoustic features extracted from these calls enabled us to discriminate the species reasonably well. The average classification performance of random forests was high for species but not for calls or segments. The call accuracy of our method was comparable to the $70 \%$ accuracy achieved using similar acoustic features and a discriminate analysis for 17 different fish call types from a submarine cave in South Africa (Ruppé et al. 2015). Additionally, the accuracy achieved for each species here was similar to the accuracy of another multi-classifier system developed for these same call types (Ibrahim et al. 2018). In both cases, red hind and Nassau grouper calls were classified with high accuracy, while discrimination of yellowfin and black grouper calls was more challenging. In comparison, our classifier performed slightly better for Nassau and black grouper calls and slightly worse for yellowfin grouper calls. Grouping both yellowfin grouper call types into one class likely made the task of discriminating these calls more challenging. However, the overall lower performance for 
black and yellowfin calls was due to the fact that the features used for discrimination were not sufficiently distinct between those 2 species and other species. A different set of features or inclusion of other call features may have aided in achieving better performance. Lastly, it is possible that misclassification of calls during logging or the quality of calls used for the analysis could have affected the performance, but we believe this to be a relatively low effect.

Two different classifiers were designed to predict call and segment type respectively, not just species. These classifiers distinguished well among the majority of call and segment types. The only call or segment that was misclassified more than by chance alone was the pulses of Nassau grouper CAS, call N2. This was due to similarities between the frequency, duration, and IPP of the single Nassau grouper pulses (Fig. 3). The tone segment of N2 calls had higher classification accuracy so using only this portion of the call, for example, would help improve the performance of classification for N2 calls using this method.

The performance of the classifier using segments was similar to call-level classification for all species with a slight increase for Nassau grouper and red hind and decrease for black and yellowfin grouper. The increase in performance observed for Nassau grouper and red hind could be due to a decrease in variability of spectral features when using shorter duration segments compared to the full call. Segments that were misclassified often, such as black grouper tones and yellowfin grouper pulse trains, had similar frequency ranges (Fig. 3D) or IPP (Fig. 3F) to the segments they were misclassified as. They also had similar durations, likely adding to the challenge. The use of another call feature, such as modulation or segment pattern, may improve the classification performance for these challenging segments.

The results of the segment classification also provided insight into the possible importance of parts of a call. For example, the call classification tree was not able to discriminate between different Nassau grouper calls, but the segment results suggest that there is at least one distinct segment in each call type. The tone of the Nassau grouper CAS (call N2) and the heartbeat pulses of the agonistic call (N3) are discriminated best for these Nassau grouper calls. These distinct segments may indicate signals with specific behavioral context such as mate selection, whereas the segments that are similar across call types, such as pulses, may function primarily for species recognition.

Our detailed comparison of the acoustic features of these calls makes it easier to understand what can cause challenges in the classification process. For example, black grouper tones can be confused with red hind tones and yellowfin grouper pulse trains while different Nassau grouper pulses are often confused with N3 pulses. This information can be used to guide development of better classifiers. The addition of information on sequencing of segments for each call type may be a useful feature to add in future developments, and a more robust classifier may be achieved by using a larger set of calls recorded from different areas and times as well. Finally, to accurately compare the performance of different classifiers, e.g. to compare our classifier with that developed by Ibrahim et al. (2018), both should be tested using the same training and testing data set.

\subsection{Temporal calling trends}

The numerous recorded epinephelid calls, many of which are thought to be CAS, contributed greatly to the biophony of this area. The analysis of longterm calling trends indicates that there is potential for acoustic competition between Nassau grouper and red hind, while temporal and spatial separation, driven most likely by FSA dynamics, may aid in acoustic partitioning for black and yellowfin grouper during the spawning period of Nassau grouper. Additionally, the results suggests that these data could also be used to develop hypotheses on spawning locations for other epinephelids, as well as the movements of Nassau grouper around the time of spawning aggregations.

There was substantial overlap in the occurrence of 3 species' calls in this study: Nassau grouper, black grouper, and red hind calls were all abundant at Site B. Red hind call occurrences were the most abundant across species at both sites. The higher number of red hind calls may indicate the presence of more individuals or higher individual call rates. If the latter, it could be a strategy to overcome propagation effects from remaining near the bottom compared to other species, to effectively communicate in a shared acoustic space, or be a result of red hind calls serving more than one purpose. For red hind, individual males form spawning territories that they defend and patrol while calling near the bottom (Shapiro et al. 1993), thus their calls may function in territorial defense and mate attraction and their propagation path may be impacted by bottom relief. Generally, the timing of peak calling for Nassau grouper and red hind overlapped in all years, occurring just after sunset. Black grouper peak calling, however, occurred 
earlier, prior to sunset. While this suggests temporal separation in calling between black grouper and the other 2 species, it is possible that acoustic partitioning may be occurring at even finer time resolutions than the $1 \mathrm{~h}$ period used in this study, as has been observed in toadfish (Thorson \& Fine 2002a). On the other hand, acoustic partitioning between yellowfin grouper and other species may be accomplished by spatial separation since yellowfin grouper calls were more abundant at Site A (during the 2016 deployment).

Differences in the timing of peak calling between years and sites may also provide clues to the location of spawning. The peak in red hind calling that occurred 2 to $3 \mathrm{~h}$ after sunset in 2015 and 2017 at Site B was not observed in 2016 at Site A. This peak may be related to spawning (Mann et al. 2010) and, if so, would suggest that preferred red hind spawning habitat is in the vicinity of Site B. For black grouper, peak calling before sunset at Site B and compared to the less prominent peak at Site A could also indicate that Site B is closer to the preferred spawning location for this species. There was a similar peak in calling at a black grouper spawning aggregation in Puerto Rico (Schärer et al. 2014) and at Riley's Hump, located in the Tortugas South Ecological Reserve, Florida (Sanchez et al. 2017). Without recordings for both sites during the same time period or knowing when peak spawning actually occurs for these species (i.e. peak spawning may have occurred outside of February during the period of data collection), we cannot be certain that these patterns are due to spawning activity and location. However, for yellowfin grouper, the peak in calling around sunset also resembled a pattern observed at a spawning aggregation in Puerto Rico (Schärer et al. 2012a), suggesting that the yellowfin grouper spawning aggregation at Little Cayman may be near Site $A_{\text {; }}$ some yellowfin grouper spawning activity was observed by divers at this site.

Yellowfin grouper are known to aggregate during the same time as Nassau grouper spawning in Belize (Heyman \& Kjerfve 2008) and likely do the same in other parts of the Caribbean (Claro \& Lindeman 2003, Nemeth et al. 2006), but spawning has more often been observed in early spring. Extended observations into spring and at more locations are necessary to understand the dynamics of yellowfin grouper FSA at Little Cayman. However, it is possible that the occurrence of peak yellowfin grouper calling in 2015 and 2017 at Site B at sunrise may be the result of fish dispersing from a yellowfin grouper FSA outside of the evening spawning hours around sunset, as observed in 2016 near Site A and in Puerto Rico (Schärer et al. 2012a).
Our recordings also indicated possible movement of Nassau grouper across the larger reef area during spawning. The dramatic increase of N2 calls in 2017 was due to the proximity of the Nassau grouper spawning aggregation to the location of the hydrophone recorders. That year, the part of the aggregation with the highest fish densities was within $100 \mathrm{~m}$ of the recorders compared to being over $300 \mathrm{~m}$ away in 2015 and 2016. The difference in diel calling patterns between 2017 and prior years was also due to the proximity of the recorder to the spawning activity. The distinct diel trend of increased N2 calls after sunset was driven by the nights of spawning and spawning-related activity, but there was also a smaller increase on all other days. The increase in N2 calls in the morning and during the day compared to night at locations farther away from the spawning aggregation in 2015 and 2016 may be an indication that fish disperse from the spawning location outside of the peak spawning period and return for spawning at night. These patterns of movement have been observed for both Nassau and yellowfin grouper in the US Virgin Islands (Rowell et al. 2015). Though the locations relative to the array, density, and spawning activity of Nassau were all corroborated by diver observations, the movements have been inferred from the temporal patterns of calling.

The decrease in Nassau call detections on the days leading up to spawning in 2015 and increase after spawning in 2016 also suggest movements of Nassau grouper to and from the spawning aggregation. Such movements have been observed by divers leading up to and following spawning. The decrease in calls observed after sunset for the other 2 call types (N1 and N3), in contrast with the increase in N2 calls in 2017, is possibly a result of a behavioral change, as spawning activity takes place during these hours. The results highlight the need for further studies of the behavioral changes within FSA and behaviors associated with sound production. Additionally, these finding have implications for future passive acoustic monitoring (PAM) at aggregations throughout the Caribbean. Researchers must be confident that recordings are in close proximity $(<100 \mathrm{~m})$ to the actual spawning site and realize that movement of fish at the aggregation site may strongly influence inter-annual results from acoustic monitoring. On the other hand, these findings also imply that the exact location of spawning sites may be inferable using calling patterns from spatially separated PAM sites and that multiple sites may be necessary to fully observe an aggregation.

The diel patterns of calling reported here are consistent with previous work, with the exception of 
Nassau grouper CAS sounds (Schärer et al. 2012b) which had a much higher increase of calls after sunset. However, Nassau grouper spawning was never observed in Grammanik Bank where those recordings were collected, and abundance was estimated to be approximately 100 fish. In contrast, the aggregation at Little Cayman included several thousand individuals (Whaylen et al. 2006), and spawning was observed in the vicinity of the recorder in 2017, thus our data likely provide better support for the expected calling pattern of CAS (call N2) at both the site of spawning and proximate locations in the greater FSA area. The location and timing of spawning was not observed for the other 3 species during our study, and it is likely that spawning occurred outside of the period or location of our data collection. Data collection over a longer time period and at more locations could help determine when and where spawning occurs for the other 3 species and provide more insight to how these 4 grouper share their environment and acoustic space.

PAM can provide valuable insights into spatial and temporal distribution, as well as behavior of fishes, but its limitations should also be considered. Attenuation and dispersion can affect the frequency content and structure of sounds, especially over long distances. In shallow water, as at our recording sites, the boundaries (e.g. the ocean bottom and surface) act as an attenuating waveguide, with the bottom reflections causing loss and both bottom and surface reflections creating multipath arrivals that can affect propagation and detection range (Kuperman \& Lynch 2004). These ranges also vary depending on ambient noise and the location of receivers (Urick 1983). In this habitat, the propagation range for these calls along the bottom is not long; likely on the order of a few $100 \mathrm{~m}$. This estimate comes from the fact that the Nassau grouper spawning aggregation was not detectable in our recordings in 2015 and 2016, even though the spawning aggregation was $<500 \mathrm{~m}$ away. A study to localize these calls relative to hydrophone location would allow a more accurate determination of the propagation distance for these calls based on calculated source levels, ultimately leading to a better understanding of the acoustic space as well as a more precise assessment of spatial partitioning and habitat preferences.

Additionally, passive acoustics can only provide information about the presence of these groupers. The absence of calls could either mean fish are not present or they are not producing sound. Previous work comparing detections of 29 tagged Nassau groupers with passive acoustic recordings of CAS indicated that fish could be present when sounds are not recorded (Tuohy et al. 2016). Similarly, we do not know if an increase in calls is related to an increase in fish numbers or an increase in the calling rate of individuals. Finally, the detection range of these sounds is needed to better assess temporal and spatial partitioning.

To fully understand why the calls of these species are separated in time, space, and frequency, other factors such as life histories and environmental variables such as temperature, tides, currents, biota, and human activity should be considered, since they may drive species distribution and calling patterns. Interestingly, Little Cayman may provide a baseline for measuring the impact of anthropogenic noise on these fish populations, since the island has a population of $<200$ people and likely lower boat presence and less human activity compared to other areas these species inhabit. It is possible that human noise impacts may be teased apart through comparison of areas with different levels and durations of exposure (Francis et al. 2009) and, if so, Little Cayman could be a valuable case study. Furthermore, the level of call description presented here may help us understand the effects of anthropogenic noise, as both inter- and intraspecific variation of acoustic signals in an environment can affect a species' abilities to respond to masking from noise (Francis et al. 2011, Radford et al. 2014).

Overall, the results of this study indicate that there is potential for interference between these calls and, therefore, possibly competition for the acoustic space at this multispecies FSA area off Little Cayman. The species studied here appear to use a combination of temporal, spatial, and spectral partitioning of the acoustic space, which could aid in effective communication. If they are competing for the acoustic space, distinct call or segment features likely aid in effective communication as well by enabling call discrimination. Passive acoustic methods can be useful to reveal important information about the acoustic environment, the spawning location, and trends of grouper species, habitat use, population structure, and status.

Acknowledgements. This research was supported by the National Science Foundation (NSF) CNS INSPIRE grant no. 1344291 issued to principal investigator C. Schurgers. K.C.W. was also supported by the US Department of Defense, Air Force Office of Scientific Research through the National Defense Science and Engineering Graduate (NDSEG) Fellowship, 32 CFR 168a. We thank C. Schurgers, J. Jaffe, and R. Kastner for their support as co-principal investigators under the NSF grant, the scientists and technicians from the Cayman Island Department of Environment for their collaboration and support of field work, and all the REEF and Grouper Moon volunteers who also supported the field work. 


\section{LITERATURE CITED}

Aalbers SA, Drawbridge MA (2008) White seabass spawning behavior and sound production. Trans Am Fish Soc 137:542-550

Amorim MCP, Vasconcelos RO, Fonseca PJ (2015) Fish sounds and mate choice. In: Ladich F (ed) Sound communication in fishes. Animal signals and communication, Vol. 4. Springer-Verlag, Vienna, p 1-33

Bass AH, Ladich F (2008) Vocal-acoustic communication: from neurons to behavior. In: Webb JF, Fay RR, Popper AN (eds) Fish Bioacoustics. Springer handbook of auditory research, Vol 32. Springer, New York, NY, p 253-278

Bass AH, Mckibben JR (2003) Neural mechanisms and behaviors for acoustic communication in teleost fish. Prog Neurobiol 69:1-26

Beets J, Friedlander A (1999) Evaluation of a conservation strategy: a spawning aggregation closure for red hind, Epinephelus guttatus, in the US Virgin Islands. Environ Biol Fishes 55:91-98

Bertucci F, Lejeune P, Payrot J, Parmentier E (2015) Sound production by dusky grouper Epinephelus marginatus at spawning aggregation sites. J Fish Biol 87:400-421

Both C, Grant T (2012) Biological invasions and the acoustic niche: the effect of bullfrog calls on the acoustic signals of white-banded tree frogs. Biol Lett 8:714-716

Bradbury JW, Vehrencamp SL (2011) Principles of animal communication. Sinauer Associates, Sunderland, MA

Breiman L (2001) Random forests. Mach Learn 45:5-32

Breiman L, Friedman JH, Olshen RA, Stone CJ (1984) Classification and regression trees. Chapman \& Hall, New York, NY

* Chek AA, Bogart JP, Lougheed SC (2003) Mating signal partitioning in multi-species assemblages: a null model test using frogs. Ecol Lett 6:235-247

* Claro R, Lindeman KC (2003) Spawning aggregation sites of snapper and grouper species (Lutjanidae and Serranidae) on the Insular Shelf of Cuba. Gulf Caribb Res 14:91-106

Codarin A, Wysocki LE, Ladich F, Picciulin M (2009) Effects of ambient and boat noise on hearing and communication in three fish species living in a marine protected area (Miramare, Italy). Mar Pollut Bull 58:1880-1887

Crawford JD, Cook AP, Heberlein AS (1997) Bioacoustic behavior of African fishes (Mormyridae): potential cues for species and individual recognition in Pollimyrus. J Acoust Soc Am 102:1200-1212

Fay RR, Popper AN (2000) Evolution of hearing in vertebrates: the inner ears and processing. Hear Res 149:1-10

Feng AS, Schul J (2007) Sound processing in real-world environments. In: Narins PM, Feng AS, Fay RR, Popper AN (eds) Hearing and sound communication in amphibians. Springer, New York, NY, p 323-350

Ficken RW, Ficken MS, Hailman JP (1974) Temporal pattern shifts to avoid acoustic interference in singing birds. Science 183:762-763

Fish JF (1972) The effect of sound playback on the toadfish. In: Winn HE, Olla BL (eds) Behavior of marine animals: current perspectives in research, Vol 2: vertebrates. Springer, Boston, MA, p 386-434

Francis CD, Ortega CP, Cruz A (2009) Noise pollution changes avian communities and species interactions. Curr Biol 19:1415-1419

Francis CD, Ortega CP, Cruz A (2011) Vocal frequency change reflects different responses to anthropogenic noise in two suboscine tyrant flycatchers. Proc R Soc B 278:2025-2031

Henry CS, Wells MM (2010) Acoustic niche partitioning in two cryptic sibling species of Chrysoperla green lacewings that must duet before mating. Anim Behav 80: 991-1003

*Heppell SA, Semmens BX, Archer SK, Pattengill-Semmens CV and others (2012) Documenting recovery of a spawning aggregation through size frequency analysis from underwater laser calipers measurements. Biol Conserv 155:119-127

Heyman WD, Kjerfve B (2008) Characterization of transient multi-species reef fish spawning aggregations at Gladden Spit, Belize. Bull Mar Sci 83:531-551

*Ibrahim AK, Chérubin LM, Zhuang H, Schärer-Umpierre MT and others (2018) An approach for automatic classification of grouper vocalizations with passive acoustic monitoring. J Acoust Soc Am 143:666-676

Kirschel ANG, Blumstein DT, Smith TB (2009) Character displacement of song and morphology in African tinkerbirds. Proc Natl Acad Sci USA 106:8256-8261

Krause BL (1987) The niche hypothesis: how animals taught us to dance and sing. Whole Earth Rev 57:14-16

Kuperman WA, Lynch JF (2004) Shallow-water acoustics. Phys Today 57:55-61

Luckhurst BE (2010) Observations of a black grouper (Mycteroperca bonaci) spawning aggregation in Bermuda. Gulf Caribb Res 22:43-49

* Ma KY, Craig MT (2018) An inconvenient monophyly: an update on the taxonomy of the groupers (Epinephelidae). Copeia 106:443-456

*Mann DA, Locascio JV, Coleman FC, Koenig CC (2009) Goliath grouper Epinephelus itajara sound production and movement patterns on aggregation sites. Endang Species Res 7:229-236

* Mann D, Locascio J, Schärer M, Nemeth M, Appeldoorn R (2010) Sound production by red hind Epinephelus guttatus in spatially segregated spawning aggregations. Aquat Biol 10:149-154

*McKibben JR, Bass AH (1999) Peripheral encoding of behaviorally relevant acoustics signals in a vocal fish: signal tones. J Comp Physiol A 184:563-576

McKibben JR, Bass AH (2001) Effects of temporal envelope modulation on acoustic signal recognition in a vocal fish, the plainfin midshipman. J Acoust Soc Am 109: 2934-2943

Moulton J (1958) The acoustical behaviour of some fishes in the Bimini (Bahama Island) area. Biol Bull (Woods Hole) 114:357-375

Myrberg A Jr (1981) Sound communication and interception in fishes. Springer, New York, NY

* Myrberg AA, Mohler M, Catala JD (1986) Sound production by males of a coral reef fish (Pomacentrus partitus): its significance to females. Anim Behav 34:913-923

*Naugler CT, Ratcliffe L (1994) Character release in bird song: a test of the acoustic competition hypothesis using American tree sparrows Spizella arborea. J Avian Biol 25:142-148

Nelson MD, Koenig CC, Coleman FC, Mann DA (2011) Sound production of red grouper Epinephelus morio on the West Florida Shelf. Aquat Biol 12:97-108

Nemeth RS, Kadison E, Herzlieb S, Blondeau J, Whiteman EA (2006) Status of a yellowfin (Mycteroperca venenosa) grouper spawning aggregation in the US Virgin Islands. Proc Annu Gulf Caribb Fish Inst 57:543-558 
Radford AN, Kerridge E, Simpson SD (2014) Acoustic communication in a noisy world: Can fish compete with anthropogenic noise? Behav Ecol 25:1022-1030

Radford CA, Ghazali S, Jeffs AG, Montgomery JC (2015) Vocalisations of the bigeye Pempheris adspersa: characteristics, source level and active space. J Exp Biol 218: 940-948

Rowell TJ, Schärer MT, Appeldoorn RS, Nemeth MI, Mann DA, Rivera JA (2012) Sound production as an indicator of red hind density at a spawning aggregation. Mar Ecol Prog Ser 462:241-250

Rowell TJ, Demer DA, Aburto-Oropeza O, Cota-Nieto JJ, Hyde JR, Erisman BE (2017) Estimating fish abundance at spawning aggregations from courtship sound levels. Sci Rep 7:3340

Rowell TJ, Nemeth RS, Schärer MT, Appeldoorn RS (2015) Fish sound production and acoustic telemetry reveal behaviors and spatial patterns associated with spawning aggregations of two Caribbean groupers. Mar Ecol Prog Ser 518:239-254

Rowell T, Schärer M, Appeldoorn R (2018) Description of a new sound produced by Nassau grouper at spawning aggregation sites. Gulf Caribb Res 29:22-26

Ruppé L, Clément G, Herrel A, Ballesta L, Décamps T, Kéver L, Parmentier E (2015) Environmental constraints drive the partitioning of the soundscape in fishes. Proc Natl Acad Sci USA 112:6092-6097

Ryan MJ, Rand AS (1993) Species recognition and sexual selection as a unitary problem in animal communication. Evolution 47:647-657

Sadovy Y, Eklund A (1999) Synopsis of biological data on the Nassau grouper, Epinephelus striatus (Bloch, 1792), and the jewfish, E. itajara (Lichenstein, 1822). FAO Fish Synop 157:1-65

Sadovy Y, Aguilar-Perera A, Sosa-Cordero E (2018) Epinephelus striatus. The IUCN Red List of Threatened Species 2018: e.T7862A46909843. http://dx.doi.org/10.2305/ IUCN.UK.2018-2.RLTS.T7862A46909843.en. (accessed 5 Jan 2020)

Sanchez PJ, Appeldoorn RS, Schärer-Umpierre MT, Locascio JV (2017) Patterns of courtship acoustics and geophysical features at spawning sites of black grouper (Mycteroperca bonaci). Fish Bull 115:186-195

Schärer MT, Nemeth MI, Mann D, Locascio J, Appledoorn RS, Rowell TJ (2012a) Sound production and reproductive behavior of yellowfin grouper, Mycteroperca venenosa (Serranidae) at a spawning aggregation. Copeia 2012:135-144

Schärer MT, Rowell TJ, Nemeth MI, Appeldoorn RS (2012b) Sound production associated with reproductive behavior of Nassau grouper Epinephelus striatus at spawning aggregations. Endang Species Res 19:29-38

Schärer MT, Nemeth MI, Rowell TJ, Appeldoorn RS (2014) Sounds associated with the reproductive behavior of the black grouper (Mycteroperca bonaci). Mar Biol 161: 141-147

Seddon N, Tobias JA (2007) Song divergence at the edge of Amazonia: an empirical test of the peripatric speciation model. Biol J Linn Soc 90:173-188
Shapiro D, Sadovy Y, Mcgehee A (1993) Size, composition, and spatial structure of the annual spawning aggregation of the red hind, Epinephelus guttatus (Pisces: Serranidae). Copeia 1993:399-406

Siemers BM, Schnitzler HU (2004) Echolocation signals reflect niche differentiation in five sympatric congeneric bat species. Nature 429:657-661

Slabbekoorn H, Bouton N, van Opzeeland I, Coers A, ten Cate C, Popper AN (2010) A noisy spring: the impact of globally rising underwater sound levels on fish. Trends Ecol Evol 25:419-427

KSueur J (2002) Cicada acoustic communication: potential sound partitioning in a multispecies community from Mexico (Hemiptera: Cicadomorpha: Cicadidae). Biol J Linn Soc 75:379-394

Tavolga W (1968) Marine animal data atlas. American Museum of Natural History, New York, NY

Tavolga WN (1971) Sound production and detection. Fish Physiol 5:135-205

*Thorson RF, Fine ML (2002a) Acoustic competition in the gulf toadfish Opsanus beta: acoustic tagging. J Acoust Soc Am 111:2302-2307

Thorson RF, Fine ML (2002b) Crepuscular changes in emission rate and parameters of the boatwhistle advertisement call of the gulf toadfish, Opsanus beta. Environ Biol Fishes 63:321-331

* Tricas T, Boyle K (2014) Acoustic behaviors in Hawaiian coral reef fish communities. Mar Ecol Prog Ser 511:1-16

Tuohy E, Schärer MT, Appeldoorn RS (2016) Spatio-temporal dynamics of a Nassau grouper spawning aggregation in Puerto Rico. Proc Annu Gulf Caribb Fish Insti 69: 319-320

Urick RJ (1983) Principles of underwater sound, $3^{\text {rd }}$ edn. McGraw-Hill, New York, NY

*Villanueva-Rivera LJ (2014) Eleutherodactylus frogs show frequency but no temporal partitioning: implications for the acoustic niche hypothesis. PeerJ 2:e496

Walker TJ (1974) Character displacement and acoustic insects. Integr Comp Biol 14:1137-1150

*Whaylen L, Pattengill-Semmens CV, Semmens BX, Bush PG, Boardman MR (2004) Observations of a Nassau grouper, Epinephelus striatus, spawning aggregation site in Little Cayman, Cayman Islands, including multispecies spawning information. Environ Biol Fishes 70 : 305-313

Whaylen L, Bush P, Johnson B, Luke KE and others (2006) Aggregation dynamics and lessons learned from five years of monitoring at a Nassau grouper (Epinephelus striatus) spawning aggregation in Little Cayman, Cayman Islands. Proc Annu Gulf Caribb Fish Inst 59:1-14

Wiggins SM, Roch MA, Hildebrand JA (2010) TRITON software package: analyzing large passive acoustic monitoring data sets using MATLAB. J Acoust Soc Am 128:2299

Winn HE (1972) Acoustic discrimination by the toadfish with comments on signal systems. In: Winn HE, Olla BL (eds) Behavior of marine animals: current perspectives in research, Vol 2: vertebrates. Springer, Boston, MA, p 361-385 


\section{Appendix.}

Table A1. Epinephelid call and segment sample size (n) for call measurements. Sample sizes for each year are shown along with the total sample size for full call feature measurements and the sample size used for call segment feature measurements and inter-pulse period (IPP)

\begin{tabular}{|c|c|c|c|c|c|c|c|}
\hline Call & n 2015 & n 2016 & n 2017 & Total $\mathrm{n}$ & Segment & $\mathrm{n}$ & n IPP \\
\hline N1 & 59 & 23 & 22 & 104 & Pulses & 104 & 104 \\
\hline N2 & 42 & 23 & 20 & 85 & $\begin{array}{l}\text { Pulses } \\
\text { Tones }\end{array}$ & $\begin{array}{l}61 \\
85\end{array}$ & 24 \\
\hline N3 & 62 & 29 & 29 & 120 & $\begin{array}{l}\text { Pulses } \\
\text { HB high } \\
\text { HB low }\end{array}$ & $\begin{array}{l}101 \\
119 \\
119\end{array}$ & $\begin{array}{l}120 \\
119 \\
106\end{array}$ \\
\hline UNK & 50 & 24 & 21 & 95 & Pulses & 95 & 95 \\
\hline RH1 & 52 & 30 & 24 & 106 & $\begin{array}{c}\text { Pulse } 1 \\
\text { Pulse } 2 \\
\text { Pulse trains }\end{array}$ & $\begin{array}{l}106 \\
106 \\
106\end{array}$ & 106 \\
\hline RH2 & 62 & 27 & 25 & 114 & $\begin{array}{c}\text { Pulses } \\
\text { Tones } \\
\text { Pulse trains }\end{array}$ & $\begin{array}{l}114 \\
114 \\
117\end{array}$ & 108 \\
\hline B & 31 & 27 & 25 & 82 & $\begin{array}{l}\text { Pulses } \\
\text { Tones }\end{array}$ & $\begin{array}{l}39 \\
82\end{array}$ & 36 \\
\hline YF1 & 0 & 46 & 15 & 61 & $\begin{array}{c}\text { Pulses } \\
\text { Tones } \\
\text { Pulse trains }\end{array}$ & $\begin{array}{l}30 \\
49 \\
58\end{array}$ & 38 \\
\hline YF2 & 5 & 29 & 27 & 61 & $\begin{array}{l}\text { Pulses } \\
\text { Tones }\end{array}$ & $\begin{array}{l}17 \\
61\end{array}$ & 13 \\
\hline
\end{tabular}

Table A2. Epinephelid call and segment training and testing sample size for random forests. Yellowfin (YF) pulses were excluded from classification due to a low sample size

\begin{tabular}{|c|c|c|c|c|c|}
\hline Call & $\begin{array}{l}\text { Training } \\
\text { size }\end{array}$ & $\begin{array}{l}\text { Testing } \\
\text { size }\end{array}$ & Segment & $\begin{array}{c}\text { Training } \\
\text { size }\end{array}$ & $\begin{array}{c}\text { Testing } \\
\text { size }\end{array}$ \\
\hline N1 & 78 & 26 & Pulses & 78 & 26 \\
\hline N2 & 63 & 22 & $\begin{array}{l}\text { Pulses } \\
\text { Tones }\end{array}$ & $\begin{array}{l}45 \\
63\end{array}$ & $\begin{array}{l}16 \\
22\end{array}$ \\
\hline N3 & 90 & 30 & $\begin{array}{l}\text { Pulses } \\
\text { HB high } \\
\text { HB low }\end{array}$ & $\begin{array}{l}75 \\
89 \\
89\end{array}$ & $\begin{array}{l}26 \\
30 \\
30\end{array}$ \\
\hline UNK & 71 & 24 & Pulses & 71 & 24 \\
\hline RH1 & 79 & 27 & $\begin{array}{c}\text { Pulse } 1 \\
\text { Pulse } 2 \\
\text { Pulse trains }\end{array}$ & $\begin{array}{l}79 \\
79 \\
79\end{array}$ & $\begin{array}{l}27 \\
27 \\
27\end{array}$ \\
\hline RH2 & 85 & 29 & $\begin{array}{c}\text { Pulses } \\
\text { Tones } \\
\text { Pulse trains }\end{array}$ & $\begin{array}{l}85 \\
85 \\
85\end{array}$ & $\begin{array}{l}29 \\
29 \\
29\end{array}$ \\
\hline B & 61 & 21 & $\begin{array}{l}\text { Pulses } \\
\text { Tones }\end{array}$ & $\begin{array}{l}29 \\
61\end{array}$ & $\begin{array}{l}10 \\
21\end{array}$ \\
\hline YF & 91 & 31 & $\begin{array}{c}\text { Tones } \\
\text { Pulse trains }\end{array}$ & $\begin{array}{l}82 \\
43\end{array}$ & $\begin{array}{c}2 \\
15\end{array}$ \\
\hline
\end{tabular}

Editorial responsibility: Stylianos Somarakis, Heraklion, Greece
Submitted: October 1, 2018; Accepted: October 30, 2019 Proofs received from author(s): January 8, 2020 